\title{
Buena administración, principio democrático y procedimiento administrativo
}

\author{
JAVIER BARNES ${ }^{1}$
}

\section{RESUMEN}

Responder al interrogante de si el derecho a la buena administración guarda alguna relación con el principio democrático, entendido primariamente como democracia representativa, implica determinar cuál es el carácter que se le atribuye al primero a partir de su consagración normativa a nivel europeo. En la medida en que la buena administración integra un conjunto de derechos procedimentales, las relaciones que mantiene con el principio democrático cobran fuerza en aquellos eventos en el que el procedimiento administrativo sirve como herramienta para aplicar la ley a casos concretos, de ordinario a través de actos administrativos singulares. Aquí el procedimiento coadyuva a la democracia, puesto que se utiliza para hacer realidad en cada caso lo que la ley democrática ha dispuesto. Por el contrario, y conforme a los elementos que según el derecho positivo integran la buena administración, las relaciones que este derecho mantiene con el principio democrático aparecen más remotas y difusas cuando el procedimiento administrativo se utiliza para completar lo que la ley ha establecido. Ante esta constatación, la presente investigación busca determinar en qué condiciones esta clase de procedimientos administrativos de

1 Catedrático de Derecho Administrativo, Universidad de Huelva, Huelva, España. Director de Global Law Press. Profesor visitante de las universidades Humbodlt y Speyer de Alemania. Doctor en Derecho, Universidad de Sevilla, Sevilla, España. Correo-e: javier. barnes@globallawpress.org. Enlace ORCID: https://orcid.org/0000-0001-7593-8835. Fecha de recepción: 30 de agosto de 2018. Fecha de modificación: 12 de septiembre de 2018. Fecha de aceptación: 24 de septiembre de 2018. Para citar el artículo: BARNES, JAVIER, "Buena administración, principio democrático y procedimiento administrativo", Revista digital de Derecho Administrativo, Universidad Externado de Colombia, n. ${ }^{\circ} 21,2019$, pp. 77-123. DOI: https://doi.org/10.18601/21452946.n21.06 
carácter creativo o innovador pueden fortalecer la legitimidad democrática de la Administración. La diferenciación de ambos conceptos - democracia y participación- permite identificar los criterios para determinar en qué condiciones la Administración se legitima a través del procedimiento.

Palabras clave: derecho a la buena administración, principio democrático, democracia representativa, procedimiento administrativo, participación ciudadana, derecho de defensa.

\title{
Good Administration, Democratic Principle and Administrative Procedure
}

\author{
ABSTRACT
}

Answer the question of whether the right to good administration has a connection with the democratic principle, primarily understood as representative democracy, entails to determine the character attributed to this right since its normative recognition at European level. Since the good administration includes a set of procedural rights, the relations it maintains with the democratic principle strengthen in those events where the administrative procedure operates as means for applying the law to particular cases through adjudication. Here the administrative procedure plays a part in democracy, because it is used to materialize what a democratic act of Congress defines. Conversely, and according to the elements that are recognized as part of the right to good administration at the European level, the relations it maintains with the democratic principle weaken when the administrative procedure is used to complete the law through rulemaking. Hence, this paper intends to determine when administrative rulemaking procedures can contribute to the democratic legitimacy of administrative agencies. The distinction between the two concepts - democracy and participation - allows us to identify under which circumstances the Public Administration can legitimate through administrative procedure.

Keywords: Right to Good Administration, Democratic Principle, Representative Democracy, Administrative Procedure, Citizen Participation, Right of Defense.

\section{EL DERECHO A LA BUENA ADMINISTRACIÓN Y LA DEMOCRACIA (REPRESENTATIVA)}

El objeto de este epígrafe preliminar reside en explorar las relaciones, siquiera sean mediatas o indirectas, que guarda el derecho a la buena administración -tal y como ha sido consagrado positivamente en la Carta Europea- y el principio democrático que recorre, y se asienta en, tantas constituciones, entendido 
primariamente como democracia representativa. Esas relaciones, como se verá de inmediato, cobran fuerza en una de las vertientes que el derecho encierra, puesto que, en la medida en que este conduce derechamente a una correcta aplicación de la legalidad democrática, contribuye a hacer realidad en cada caso concreto lo que el parlamento, como legítimo representante del pueblo, ha dispuesto.

Por el contrario, si atendemos al perímetro del derecho a la buena administración, esto es, a los elementos que este integra según el derecho positivo en nuestro tiempo, dejando al margen lo que doctrinal -y legislativamente en el futuro- pueda desplegar, las relaciones con el principio democrática son más remotas y difusas en otros escenarios, señaladamente cuando el ciudadano entra en contacto con la Administración para participar y colaborar en procedimientos administrativos de última generación ${ }^{2}$.

Veámoslo más despacio.

\subsection{El DERECHO A LA BUENA ADMINISTRACIÓN COMO DERECHO DE CARÁCTER PROCEDIMENTAL}

El derecho a una buena administración en realidad integra un conjunto de derechos procedimentales, que en última instancia se traducen en su mayor parte en derechos de defensa ${ }^{3}$.

2 Aquí se utiliza el término "procedimiento administrativo" como valor entendido en tantos ordenamientos para hacer referencia al modo de resolver y actuar de la Administración, y se distingue y diferencia claramente del proceso judicial en el que la Administración sea parte.

3 La versión inglesa dispone:

"Article 41 Right to good administration.

1. Every person bas the right to bave bis or her affairs bandled impartially, fairly and within a reasonable time by the institutions, bodies, offices and agencies of the Union.

2. This right includes: (a) the right of every person to be beard, before any individual measure which would affect bim or her adversely is taken, $(b)$ the right of every person to bave access to bis or ber file, while respecting the legitimate interests of confidentiality and of professional and business secrecy ${ }_{i}(c)$ the obligation of the administration to give reasons for its decisions.

3. Every person has the right to bave the Union make good any damage caused by its institutions or by its servants in the performance of their duties, in accordance with the general principles common to the laws of the Member States.

4. Every person may write to the institutions of the Union in one of the languages of the Treaties and must bave an answer in the same language" (disponible en línea https://eur-lex.europa.eu/legal-content/ EN/TXT/?uri=CELEX:12012P/TXT).

La versión española, en una traducción oficial poco técnica y elegante (en particular en su apartado 2.a), dice así:

"Artículo 41. Derecho a una buena administración.

1. Toda persona tiene derecho a que las instituciones, órganos y organismos de la Unión traten sus asuntos imparcial y equitativamente y dentro de un plazo razonable. 
En efecto, toda persona, de acuerdo con su consagración positiva, tiene derecho a una resolución fundada en derecho y, más en concreto, a que los asuntos que le afecten se resuelvan de modo imparcial, equitativo y en un tiempo razonable (artículo 41.1). Exigencias estas que de ordinario se satisfacen en el seno de un procedimiento administrativo, bien se sustancie este en la clásica secuencia de actos de autoridad, a modo de canal formalizado y ordenado temporalmente, o bien se reduzca a directrices o principios -sin plazos o trámites específicos- sobre el modo de resolver, como los que cita el propio precepto (imparcialidad, equidad, sin dilaciones). A tal propósito, el derecho comprende, añade el artículo 41.2, otros derechos de carácter procedimental, íntimamente relacionados, al servicio de la defensa del afectado, tales como la previa audiencia del interesado, el acceso a la información necesaria para la defensa y la motivación de la decisión, lo que permitirá, en su caso, impugnar o cuestionar la decisión sobre la base de los razonamientos en que se funde. A ello se añade el derecho a expresarse ante las autoridades en cualesquiera de las lenguas reconocidas, derecho este que, aunque despliega una particular fuerza cuando se trata de la tutela de los derechos e intereses individuales, no se contrae al clásico procedimiento que desemboca en el dictado de un acto administrativo singular ${ }^{4}$.

\subsection{El Derecho a la buena administración (artículo 41 de la Carta EUROPEA DE DERECHOS FUNDAMENTALES) Y EL PRINCIPIO DEMOCRÁTICO}

La específica cuestión previa que aquí interesa desvelar es si el derecho a la buena administración, en los términos que ha sido plasmado normativamente, guarda alguna relación con el principio democrático, tal y como luce en tantas

2. Este derecho incluye en particular: a) el derecho de toda persona a ser oída antes de que se tome en contra suya una medida individual que la afecte desfavorablemente $e_{i}$ b) el derecho de toda persona a acceder al expediente que le concierna, dentro del respeto de los intereses legítimos de la confidencialidad y del secreto profesional y comercial ${ }_{i}$ c) la obligación que incumbe a la administración de motivar sus decisiones.

3. Toda persona tiene derecho a la reparación por la Unión de los daños causados por sus instituciones o sus agentes en el ejercicio de sus funciones, de conformidad con los principios generales comunes a los derechos de los Estados miembros.

4. Toda persona podrá dirigirse a las instituciones de la Unión en una de las lenguas de los Tratados y deberá recibir una contestación en esa misma lengua (disponible en línea https://eur-lex.europa.eu/legal-content/ES/TXT/HTML/?uri=CELEX:12012P/TXT\&from=EN). El derecho a una buena administración es, pues, un derecho de contenido un tanto heterogéneo, conocido en los ordenamientos nacionales de los Estados miembros de modo individualizado, con frecuencia a través de la legislación de procedimiento administrativo, a veces en las mismas Constituciones. En la Carta Europea adquiere carácter de derecho fundamental ante y frente a las instituciones de la Unión Europea, en primera instancia. La misma consagración de la responsabilidad se reconoce en ocasiones en la misma legislación de procedimiento (ese fue el caso, por ejemplo, de la Ley 30/1992 española. 
constituciones contemporáneas. Lo cual es tanto como preguntarse cuál es la relación que guarda el procedimiento administrativo con la democracia representativa, habida cuenta de que, como se ha notado, el precitado derecho se resuelve de ordinario en normas de procedimiento.

Así las cosas, podríamos decir que el procedimiento administrativo tiene implicaciones con el principio democrático en dos grandes supuestos: cuando el procedimiento administrativo sirve como herramienta para aplicar la ley a cada caso, de un lado, y, de otro, cuando el procedimiento administrativo se utiliza para completar lo que la ley ha establecido. Lo primero se produce en particular cuando la ley ha predeterminado la solución y mediante el procedimiento se persigue el acierto en la decisión, esto es, garantizar que se cumple la voluntad democrática expresada en la ley (si procede o no otorgar una licencia o imponer una sanción, por ejemplo), el segundo, en cambio, tiene lugar cuando la ley deja un amplio espacio a la Administración para que resuelva (como en el caso del planeamiento urbanístico) y le confía a un procedimiento participativo el desarrollo material o sustantivo de la ley (la creación de ciudad).

En ambos casos, el procedimiento administrativo está implicado en el circuito democrático, aunque de modo distinto: en uno porque aplica la ley democrática; en otro porque contribuye a fortalecer -y completar- la legitimidad democrática de la acción administrativa mediante la participación y colaboración de actores privados y públicos.

- La primera y más clásica relación entre el procedimiento y el principio democrático se da, pues, cuando el procedimiento administrativo constituye el instrumento por excelencia que posee la Administración para llevar a efecto lo que la ley -expresión de la voluntad popular- haya establecido para cada caso. En ese contexto, se entiende la tradicional afirmación de que un ejecutivo "fuerte" o, si se prefiere, una Administración capaz de aplicar con diligencia lo que la ley haya dispuesto, se erige en un requisito sine qua non para que la democracia se haga efectiva. El procedimiento se erige así en instrumento al servicio de la democracia, en la medida en que hace posible que las decisiones que se ha dado el pueblo a través de sus representantes en el parlamento se hagan realidad ${ }^{5}$.

- La segunda relación reside en la función legitimadora que el procedimiento pueda satisfacer en los casos en que este se utiliza para completar el

5 Un Estado es lo que su Administración. El parlamento puede tomar las más sabias y democráticas decisiones sobre medio ambiente, urbanismo, política económica, educación o sanidad, por ejemplo. Ahora bien, sin una Administración que organice la vida en sociedad -la realización de esas decisiones- nada se alcanza. A esta constatación empírica e histórica se añade aquí que, sin esa intervención de la Administración -bien sea para dirigir, incentivar, supervisar o prestar por sí- tampoco se haría realidad el ideal democrático. La Administración, pues, no es solo la realizadora de las leyes, sino la que cierra el circuito democrático. 
contenido mínimo legalmente establecido, siempre y cuando la participación pública cumpla determinadas condiciones, a las que luego se aludirá ${ }^{.}$

Por decirlo gráficamente, cabe hablar a nuestro limitado propósito de dos clases de procedimientos administrativos: "aplicativos" o meramente ejecuti-

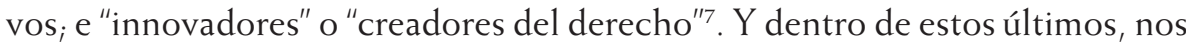
importan ahora aquellos de última generación en los que, justamente por esa condición innovadora y no meramente aplicativa de la ley, la participación se erige en eje y centro.

\subsection{CONCLUSIÓN: LA DIVERSA RELACIÓN DE LAS DIMENSIONES DEMOCRÁTICAS DEL PROCEDIMIENTO ADMINISTRATIVO}

Como se desprende de cuanto ha quedado dicho, la primera dimensión (el procedimiento como instrumento de aplicación de la ley y el derecho) late, como en segundo plano, en el derecho a una buena administración. En él, como se ha visto, se reconocen valores -traducibles en derechos para el ciudadano y en deberes para la Administración- que pretenden garantizar el acierto de la Administración en la aplicación de la legalidad democrática y en la tutela de los derechos e intereses ciudadanos, que igualmente forma parte de esa legalidad. Una aplicación de la ley y el derecho que sea imparcial, equitativa, a tiempo, atenta a las alegaciones del interesado, transparente o motivada -pues en eso se resuelve en esencia la buena administración- constituye una ejecución del derecho que sirve a la democracia, que lleva a su puro y debido efecto lo que la democracia representativa ha establecido. El derecho a la buena administración tiene, pues, como telón de fondo el principio democrático. La relación entre ambos polos, aunque mediata, resulta reconocible. Una aplicación escrupulosa de la legalidad significa hacer realidad la democracia. Y, a la inversa, una aplicación desviada de la legalidad no solo hace de ese acto jurídico un acto "técnicamente" ilegal, sino, además, contrario al principio democrático, es decir, deviene en un acto antidemocrático.

6 Así, por ejemplo, cla información pública previa a la aprobación de un plan, tal y como en encuentra reconocida en el derecho español, es susceptible de otorgarle por sí sola un plus de legitimidad? ¿Y la participación que tiene lugar en el seno de las Administraciones funcionales dotadas de autonomía, como la universidad? ¿Y la consulta pública celebrada por la Unión Europea sobre el cambio horario, a la que se ha aludido? La respuesta a estos interrogantes, como habrá ocasión de abundar, es resueltamente negativa, porque esas fórmulas participativas no reúnen las condiciones para alcanzar esa virtualidad legitimadora. Tendrán otras virtudes, pero no fortalecen la democracia.

7 El procedimiento administrativo sancionador o el autorizatorio de una licencia reglada constituirían ejemplos del primer grupo, mientras que el procedimiento de aprobación del planeamiento urbanístico, de una licencia ambiental integrada o la autorización de un nuevo medicamento, por ejemplo, lo serían del segundo. 
La segunda vertiente (el procedimiento como técnica para completar el contenido democrático de la ley), según notábamos, no guarda relación con el indicado derecho (aunque sí con la democracia), puesto que este parece pensar en aquellos procedimientos clásicos o tradicionales, que concluyen con un acto administrativo singular, potencialmente desfavorable o restrictivo de derechos -de ahí los derechos de defensa-. Y no se preocupa, en cambio, por los procedimientos administrativos de amplia participación, en los que no se ventilan (prioritariamente al menos) derechos o intereses individuales, sino derechos difusos o colectivos, o, más ampliamente, cuestiones de políticas públicas (urbanismo y ordenación del territorio, medio ambiente y salud pública, entre tantos), procedimientos que por ello se expresan no solo en actos singulares, sino en toda clase de actos jurídicos (generales, reglamentos, planes, programas, evaluaciones e informes, por ejemplo).

Solo si se hiciera una interpretación expansiva de los derechos que enumera el citado artículo 41 de la Carta podrían entenderse indirectamente aludidos estos otros procedimientos administrativos de carácter creativo e innovador ${ }^{8}$. Para ello, y a falta de un reconocimiento más explícito en el derecho positivo, cabría conectar el referido precepto con el artículo 10.3 del Tratado de la Unión Europea, de acuerdo con el cual "Todo ciudadano tiene derecho a participar en la vida democrática de la Unión. Las decisiones serán tomadas de la forma más abierta y próxima posible a los ciudadanos". Este precepto, sin embargo, no establece cuáles sean esos derechos de participación, ni en qué consista esa "vida democrática de la Unión", que podría canalizarse a través de múltiples fórmulas (consultas públicas, vinculantes o no; encuestas; y derecho de petición, por ejemplo), sin conexión directa con los derechos procedimentales que el derecho a la buena administración encierra9 ${ }^{9}$.

Que no quepa anclar la problemática propia de los procedimientos administrativos de carácter creativo o innovador en el derecho a la buena administración -hoy y ahora-, no significa, sin embargo, que no hayan de explorarse las relaciones que estos encierran, cuando se estructuran en torno a una amplia participación, con la democracia (representativa). Y aun cuando este grupo de procedimientos no se encuentre aludido en el derecho fundamental a la buena administración, no por ello deja de encontrar de un modo u otro apoyo

8 Esa relación siempre estaría presente, por ejemplo, en lo que se refiere a la lengua con la que se dirija el ciudadano a la Administración, la responsabilidad extracontractual, la obligación de contestar o resolver lo planteado, entre otros. Pero no es esa la perspectiva que interesa. Aquí nos ocupamos de los procedimientos de carácter creativo e innovador, no puramente aplicativos, equipados, eso sí, de una amplia participación.

9 El citado artículo 10.3 (TUE), a nuestro juicio, no establece por sí, en efecto, "derechos de participación" en el seno de procedimientos administrativos. 
explícito en el derecho primario de la Unión Europea ${ }^{10}$ y, más aún, en el secundario ${ }^{11}$; en las constituciones nacionales ${ }^{12}$ y también en los tratados ${ }^{13}$. La construcción de esta clase de procedimientos es, con todo, una obra de la legislación ordinaria.

En resumen, la estrategia de extender el derecho del artículo 41 de la Carta a este ámbito, además de forzada, resulta innecesaria. El derecho a una buena administración opera en realidad como broche de cierre para dar cobijo a toda una serie de derechos bien conocidos, aunque no agota las cuestiones esenciales de las relaciones ciudadano-Administración.

Seguidamente, nos ocupamos de indagar cuál es la relación que mantiene esta clase de procedimientos de carácter innovador o creativo, y amplia participación con la democracia representativa o, lo que es lo mismo, en qué condiciones puede sostenerse que esta clase de procedimientos administrativos complementa la legitimidad democrática de la Administración cuando aplica leyes que difieren la decisión sustantiva a lo que ello se resuelva.

\section{LA PROCEDIMENTALIZACIÓN DEL DERECHO. CUANDO LA DECISIÓN DE FONDO SE TRANSFIERE A LA ADMINISTRACIÓN}

La Comisión Europea ha celebrado una consulta ciudadana en la Unión Europea -integrada por 500 millones de habitantes ${ }^{14}$ - en la que pregunta en forma de encuesta si se estaría a favor de abandonar el cambio horario que se produce todos los años y, en caso afirmativo, qué hora preferiría, la de verano o la de invierno ${ }^{15}$. La encuesta ha tenido una participación récord $-4,6$ millones

10 Sirva de ejemplo el citado artículo 10.3 TuE y, entre la jurisprudencia reciente, la Sentencia del 4 de septiembre de 2018, de la Gran Sala del Tribunal de Justicia de la Unión Europea

11 El derecho de la Unión Europea en materia de medio ambiente -que se traduce en buena medida en normas de procedimiento- contempla mecanismos de amplia participación, como es bien sabido, respecto de los principales instrumentos y mecanismos. Baste pensar en la evaluación de impacto ambiental, en la evaluación estratégica ambiental o en las licencias integradas.

12 También, a mero título de ejemplo, puede verse, en relación con las disposiciones generales (reglamentos en particular), lo dispuesto en el artículo 105.a de la Constitución española de 1978: "La audiencia de los ciudadanos, directamente o a través de las organizaciones y asociaciones reconocidas por la ley, en el procedimiento de elaboración de las disposiciones administrativas que les afecten".

13 Significativo y emblemático resulta el Convenio de Aarhus sobre acceso a la información, participación del público en la toma de decisiones y acceso a la justicia en materia de medio ambiente, que regula los derechos de participación ciudadana.

14 En 2015, 508. Cfr. https://europa.eu/european-union/sites/europaeu/files/docs/body/ eu_in_slides_es.pdf.

15 Cfr. https://ec.europa.eu/info/consultations/2018-summertime-arrangements_es\#aboutthis-consultation. 
de respuestas-, la mayor parte provenientes de Alemania, y el resultado ha sido contrario al tradicional cambio de horario. Prensa y políticos hablan de que "Europa se ha pronunciado a favor de suprimir el cambio horario". Y, sin embargo, cesa participación hace más democrática la decisión que proponga finalmente la Comisión, caso de seguir el resultado de esa encuesta? ¿Es suficientemente representativa, tanto por el número de participantes, como por sus lugares de proveniencia?

En la conciencia popular, y en la jurídica en ocasiones, se tiende a pensar que cuanto mayor sea la participación ciudadana en el procedimiento decisorio de la Administración, tanta más legitimidad democrática ostentará la resolución que se adopte. Afirmación esta que, sin embargo, no resiste un análisis más profundo, si no es con muchos matices y cautelas. En momentos históricos en los que la democracia representativa o parlamentaria parece hallarse en crisis, esa simplificación ("cualquier forma de participación contribuye a fortalecer la democracia") gana adeptos. Sin embargo, una mayor precisión conceptual de las coordenadas jurídicas que enmarcan la democracia en nuestras sociedades y Estados constituye un presupuesto necesario para un debate riguroso. Entender la democracia es hoy una tarea urgente.

Antes de abundar en los procedimientos de carácter creativo o innovador y las condiciones para que fortalezcan la legitimidad democrática de la Administración (6), conviene apuntar el entorno en que sitúan (1-5).

\subsection{LA "DESMATERIALIZACIÓN" DE LA LEY}

Una de las señas de identidad de nuestro tiempo -por su carácter simbólico y representativo de temas de más hondo calado- podría sintetizarse en la tendencia hacia la "procedimentalización del derecho". El derecho del medio ambiente de matriz europea, por ejemplo, se halla fuertemente "procedimentalizado", al igual que acontece con la legislación relativa al urbanismo, la seguridad alimentaria, las sustancias químicas, la contratación pública, la regulación de los mercados financieros o los medicamentos, entre tantos otros. En esos y otros sectores sobreabundan las normas de procedimiento. El legislador pone el acento en cómo ha de actuar y proceder la Administración en un ámbito determinado, y no en qué deba hacer en cada caso. Así, decide cómo se crea ciudad, y no cuál haya de ser el concreto modelo de ciudad en cada tiempo y lugar. El procedimiento compensa la incapacidad de la ley para dirigir a la Administración, sustituye a lo que no es formulable con carácter previo en términos sustantivos ${ }^{16}$.

16 Así, Eberhard SChmidt-Assmann, "Der Verfahrensgedanke in der Dogmatik des öffentliches Rechts", en Verfabren als staats- und verwaltungsrechtliche Kategorie, Heidelberg: R. v. Decker \& C. F. Müller, 1984, p. 5. 
Esta expresión -la procedimentalización del derecho- la entendemos aquí, a nuestro limitado propósito y desde la óptica del derecho administrativo, como una respuesta alternativa a la pérdida de capacidad directiva de la ley para anticiparse a la realidad o, lo que es lo mismo, para determinar a priori la solución que a tantos problemas y situaciones haya de darse. Ello trae como consecuencia que la ley apueste por un contenido más procedimental que sustantivo, esto es, que se ocupe más sobre cómo resolver y decidir un problema de futuro, y menos de predecir cuál haya de ser la exacta solución del caso. Lo que es tanto como admitir que la ley se ve abocada en tantos supuestos a abdicar de su posición tradicional, en cuanto instancia decisora sobre el fondo del asunto, en favor de la Administración.

La ley, por ejemplo, no puede decidir si un nuevo medicamento podrá o no comercializarse en el futuro, aun cuando establezca a ese propósito directrices, objetivos y garantías, pero sí podrá disponer cómo ha de adoptarse tal decisión (con amplio consenso científico y sin interferencias de los laboratorios). La ley, en efecto, predetermina el cómo, no el si. En ese sentido, decimos que se trata de una ley procedimental, antes que sustantiva ${ }^{17}$.

La consiguiente procedimentalización del derecho explica asimismo que se haya desdibujado la clásica separación entre el momento legislativo y su ulterior ejecución a cargo de la Administración. De acuerdo con el planteamiento clásico de la división de poderes (y de la distribución de competencias), se trata de un esquema bifásico en el espacio y en el tiempo: la ley decide y la Administración aplica. Ahora bien, si la ley difiere qué hacer al momento "aplicativo" que a la Administración corresponde, y es en el seno del procedimiento que esta impulsa donde ha de generarse el criterio o la solución de fondo, la nítida diferenciación entre legislación y ejecución tenderá a disolverse. Es este un fenómeno bien conocido (como ha venido ocurriendo, entre otros, con la creación de ciudad a través del planeamiento urbanístico), hoy multiplicado exponencialmente.

En un entorno marcado por el riesgo y la incertidumbre, amplios sectores del ordenamiento - medio ambiente, seguridad, tecnología, ciencia, mercados financieros, etc. - ya no se dejan gobernar por leyes omniscientes y una Administración que opera como si fuere una simple correa de transmisión, esto es, limitada a recoger los impulsos legislativos y a aplicar con cierto automatismo lo que de estos se derive. A su vez, este mismo fenómeno da paso a la era de las súper-agencias, o súper-administraciones, ocupadas de preservar la estabilidad

17 Asistimos a una suerte de erosión o "desmaterialización" de la programación legislativa. Véase, por ejemplo, Helge Rossen-Stadtfeld, "Beteiligung, Partizipation und Öffentlichkeit" en Grundlagen des Verwaltungsrechts, II, 2. ${ }^{a}$ ed., München: Beck, 2012, p. 711. No quiere ello decir que la procedimentalización del derecho se resuelva, y se agote, en procedimientos administrativos (numerosas normas prescriben cómo hacer las cosas sin que ello remita necesariamente al procedimiento administrativo). 
financiera; la seguridad alimentaria o aérea ${ }_{i}$ la salud pública o la prestación de servicios de interés general en régimen de mercado, como la energía y las telecomunicaciones, por tan solo citar algunos ejemplos, en un panorama, además, nótese bien, condicionado por la globalización y la privatización. No ha de olvidarse en ese sentido que históricamente la legislación de procedimiento comenzó apostando por una amplia participación precisamente para que a su través la Administración pudiera obtener la información necesaria que se halla en manos del sector privado y de ese modo tomar la decisión más adecuada ${ }^{18}$.

\subsection{DeCIDIR SObRE CÓMO DECIDIR}

Así las cosas, el procedimiento administrativo viene a "completar" ese espacio que le confía la ley y a asumir una función de dirección política, técnica y científica de la que antes carecía, pues en estos casos no se pretende, mediante el procedimiento, "descubrir" lo que la ley haya dispuesto para el caso concreto, esto es, no se trata de "aplicar el derecho" como si de un juez se tratara, puesto que la ley guarda silencio, sino de algo muy distinto: de "inventar" la mejor solución material que la ley ha diferido a la Administración o, si se prefiere, de "crear derecho", justamente mediante un procedimiento administrativo "de gama alta". El procedimiento administrativo es entonces el lugar o foro en que se generan los criterios, las directrices, las normas y los estándares con la ayuda de la participación y el debate; se elaboran los planes, los programas y el planeamiento territorial, o se encuentran las soluciones para situaciones generales o singulares. No se trata ya de concretar o desarrollar, sino de crear. El procedimiento administrativo entra a formar parte del proceso político: la

Los estudios de la comisión nombrada por el propio presidente Roosevelt para la preparación de la ley federal norteamericana de procedimiento administrativo que tuvieron lugar entre 1939 y 1941 subrayaron este último aspecto, en la convicción de que el sector privado posee los conocimientos técnicos y científicos que la Administración necesita para gobernar adecuadamente. Véase Final Report of the Attorney General's Committee on Administrative Procedure (Senate Document n. ${ }^{\circ} 8,77^{\text {th }}$ Congress, First Session, 1941), en Felix FrankfurTer, "The Final Report of the Attorney General's Committee on Administrative Procedure: Foreword", Columbia Law Review, n. ${ }^{\circ}$ 41, New York: Columbia University, 1941. Me remito a mi trabajo "El procedimiento administrativo en el tiempo y en el espacio: una perspectiva histórica y comparada", en la obra colectiva (seis volúmenes) dirigida por Héctor Pozo Gowland y otros, Procedimiento administrativo. Aspectos generales del procedimiento administrativo, t. I, Buenos Aires: La Ley, 2012, pp. 145-259. Desde otra perspectiva, Maurizia DE Bellis recuerda -respecto del ámbito europeo- que la participación cumple cuando menos una doble función: la obtención del conocimiento experto y técnico necesarios, que se halla en manos del sector privado, en términos de eficacia y calidad de la regulación, de un lado, $y$, de otro, la contribución a la democracia deliberativa y, en definitiva, al fortalecimiento de la legitimidad de las agencias. Cfr. "Procedural rule-making of European Supervisory Agencies (ESA). An effective tool for legitimacy?", TARN Working Paper Series, n. 12 , Maastricht: Universidad de Maastricht, 2017. 
Administración ejerce su capacidad de configuración de la sociedad a través del procedimiento ${ }^{19}$.

Con la procedimentalización del derecho, pues, no se alude simplemente a una mayor dependencia del procedimiento administrativo en el seno del derecho administrativo, sino a algo más: a la función específica -de creación e innovación-que le compete desplegar en esos escenarios ${ }^{20}$.

Ahora bien, no se trata en estos casos de un procedimiento administrativo cualquiera, como es obvio, sino de procedimientos de mayor responsabilidad, basados en una intensa participación, entre otras razones porque tampoco la Administración lo sabe todo. De ahí que una amplia participación (interesados, público en general, expertos, otras Administraciones) pretenda satisfacer esa necesidad imperiosa: hallar entre todos, bajo la dirección de la Administración responsable, la solución en cada caso más adecuada. El legislador decide cómo ba de decidir la Administración (con una amplia participación).

El hecho de que la ley material no pueda dirigir a la Administración en la forma en que idealmente lo venía haciendo no significa que le sea lícito abdicar de la función democrática y de dirección de la Administración que al parlamento incumbe ${ }^{21}$. La ley -su función respecto de la Administración- ha de "reinventarse" o, por mejor decir, redescubrirse; han de ensayarse nuevos caminos. Y el procedimiento es uno de ellos, cuya configuración en sede parlamentaria deja de ser un tema adjetivo o menor para convertirse en una estrategia reguladora de primer nivel, con efectos trascendentes y multiplicadores.

En efecto, las disposiciones procedimentales tienen la virtualidad de condicionar y determinar decisivamente lo que la Administración en cada caso pueda resolver ${ }^{22}$. Esta opción no constituye solo un modo de satisfacer las exigencias de las reservas legales allí donde existan ${ }^{23}$, sino también de dar cumplimiento

19 Puede verse sobre el tema, Hans Heinrich Trute, "Die demokratische Legitimation der Verwaltung", en Grundlagen des Verwaltungsrechts, vol. I, 2. ${ }^{a}$ ed., München: Beck, 2012, p. 345.

20 En sentido análogo, ibíd., p. 375.

21 Es un deber que se construye sobre los mencionados principios y postulados. Así, por ejemplo, en la Constitución española: artículos 1.1 (Estado democrático y social de derecho), 9.3 (principio de legalidad), 53.1 (vinculación a los derechos fundamentales) y 103.1 (vinculación de la Administración a la ley y al derecho). Si los legisladores del urbanismo o el de la supervisión bancaria, por ejemplo, no pueden establecer suficientes directrices o estándares sustantivos para la acción futura de la Administración municipal o del banco central, respectivamente, ello no supone que el parlamento deba conformarse con esa limitación, como si de una patología insalvable se tratara.

22 Si el legislador del urbanismo quiere evitar la centrifugación de las zonas verdes hacia la periferia, podría establecer un obligado procedimiento participativo a cargo del municipio, en el que todos los vecinos pudieran ejercer una influencia real expresando su opinión, como si de una evaluación estratégica ambiental se tratase, para oponerse a un proyecto tal.

23 La importancia que ha experimentado el procedimiento se pone de manifiesto en la propia jurisprudencia sobre la reserva de ley, para formar parte de su núcleo. Sobre esta temática, véase Hans HeinRICH Trute, óp. cit., pp. 375 y ss. 
al principio de vinculación de la Administración a la ley y al derecho y, más ampliamente, al principio de legalidad. De esos principios cabe derivar el deber jurídico que pesa sobre el legislador de decidir-cuando menos-sobre cómo decidir y, por tanto, sobre el procedimiento ${ }^{24}$. El legislador, al resolver sobre el procedimiento a seguir, condiciona y determina el sector de que se trate, al tiempo que mejora la legitimidad interna que la ley genera.

Sea como fuere, la emergencia de una Administración "menos ejecutiva" y "más discrecional" ${ }^{25}$ plantea el interrogante de la (in)suficiencia de los mecanismos y canales tradicionales de legitimidad democrática de la Administración. Las páginas que siguen, sin embargo, se contraen, sin perjuicio de su contextualización ${ }^{26}$, a explorar un único punto, como se ha dicho: en qué condiciones la participación en el seno del procedimiento posee la virtualidad de otorgar una mayor legitimidad democrática ${ }^{27}$.

\section{DE UNA ADMINISTRACIÓN EJECUTANTE \\ A UNA ADMINISTRACIÓN (TAMBIÉN) \\ AUTOPROGRAMABLE. LA PREOCUPACIÓN \\ POR LA LEGITIMIDAD DEMOCRÁTICA \\ DE LA ADMINISTRACIÓN CORRE PARALELA \\ AL CRECIMIENTO DEL ESPACIO PROPIO \\ QUE A ESTA SE LE ATRIBUYE}

\subsection{LA IMAGEN DE UNA AdMINISTRACIÓN CON PODERES EJECUTIVOS}

Si la Administración constituyera una mera correa de transmisión al servicio del legislador, no habría que preocuparse en exceso por la legitimidad democrática de aquélla, o al menos no habría que hacerlo en los términos que hoy se suscitan. Al fin y al cabo, se trataría de una Administración limitada a aplicar de modo cuasi-automático y sin margen significativo alguno una ley democráticamente aprobada. Ese ha sido el modelo teórico, o la imagen característica, que se ha tenido de la Administración durante un largo período histórico.

24 También sobre otros elementos o premisas estratégicas que condicionan en distinta medida y un efecto difuso las decisiones de futuro, como la organización, el personal o los presupuestos.

25 Esta construcción jurídica, en clave de enjuiciamiento, no da cuenta suficientemente del fenómeno de la Administración autoprogramable que aquí se describe.

26 Véase apartados 3-5.

27 Véase apartados 6 y ss. 


\subsection{El RECONOCIMIENTO DE QUE LA AdMINISTRACiÓn DESPLIEGA AMPLIAS POTESTADES QUE NO SE EJERCEN AL DICTADO DE UNA PREVIA LEY MATERIAL}

En nuestro tiempo, sin embargo, se admite ya sin reservas que la Administración actual se halla muy lejos de ser una Administración meramente "ejecutante" o aplicadora de leyes emanadas del parlamento. En tantos casos resulta más apropiada la imagen de una Administración "autoprogramable", que opera dentro de un marco normativo que le deja un espacio muy amplio, como sucede, por ejemplo, con un banco central nacional o, más aún, con el Banco Central Europeo.

Como es sabido, la teoría democrática ha crecido por referencia al poder legislativo. $\mathrm{O}$, por decirlo en otros términos, el Estado contemporáneo se ha construido sobre la idea de la democracia representativa o parlamentaria. Su proyección sobre el Ejecutivo y la Administración habría de esperar. De hecho, el principio democrático que luce en las constituciones entra en la dogmática del derecho administrativo de corte europeo-continental hace pocas décadas ${ }^{28}$. Es entonces cuando la doctrina comienza a estudiar cómo fundamentar la legitimidad democrática de la Administración, más allá de la clásica teoría de la cadena de transmisión de la legitimación democrática ${ }^{29}$, en escenarios muy diversos a los que la vieron nacer; esto es, cuando la Administración goza de un amplio margen de decisión o, más sencillamente, se interrumpe esa cadena de transmisión. Desde ese momento, el problema no ha hecho sino crecer exponencialmente y la cuestión se ha convertido en un elemento esencial del derecho administrativo (contemporáneo), uno de cuyos últimos capítulos lo representa la legitimidad democrática de las Administraciones independientes ${ }^{30}$.

\subsection{El Estado democrático}

Acaso ese retraso o desproporción entre el tratamiento que recibe el principio del Estado de derecho y el que se le otorga al principio democrático guarde relación con el propio nacimiento del derecho administrativo, preocupado como ha estado históricamente, en una lenta y larga conquista -siempre inacababapor sujetar a la Administración con la ley -"embridar el poder con el derecho",

28 Por ejemplo, en Alemania se cifra en torno a la década de los sesenta del pasado siglo (véase Hans HeinRich TRUTE, óp. cit., p. 344). En otros países, sin embargo, el interés ha sido mucho más tardío.

29 Transmisión desde el pueblo hasta la decisión administrativa: de los representantes del parlamento elegidos por el pueblo, sale el presidente, que, a su vez, nombra a la cúspide de la Administración (ministerios), y así sucesivamente. Sobre este modelo tradicional, véase EberhaRd SChmidt-Assmann, La teoría general del derecho administrativo como sistema, Madrid: Marcial Pons - INAP, 2003, capítulo segundo, núm. 82 y ss.

30 Véase por todos Paul TuCKer, Unelected Power: The Quest for Legitimacy in Central Banking and the Regulatory State, Nueva Jersey: Princeton University Press, 2018. 
diría E. García de Enterría-. Se trataba de domesticar a la Administración. El principio arquitectural en liza y que acapararía toda la atención ha sido, en efecto, el principio del Estado de derecho, no el principio democrático. Urgía construir la vinculación de la Administración a la ley y al derecho, apurar el principio de legalidad, reservar al legislador las cuestiones fundamentales, asegurar la tutela de los derechos e intereses frente al Ejecutivo y las Administraciones, controlar judicialmente la discrecionalidad ${ }^{31}$. En ese contexto, no cabía pensar siquiera, y menos aún aceptar, como un fenómeno natural, en una Administración desvinculada de la ley, sin instrucciones precisas del legislador. La preocupación prioritaria de esta primera fase histórica radica en controlar, o contrastar, si la acción administrativa cumple u observa lo que el legislador ha dispuesto, y no en cambio su legitimidad democrática. En una atmósfera de desconfianza, en la que la pugna consistía -y consiste- en extender el manto de la legalidad a toda acción administrativa, no parece fácil asumir que la Administración pueda ostentar una capacidad propia para configurar la vida social y económica, y operar con un amplio margen de maniobra, con funciones y responsabilidades específicas, máxime a luz de un concepto estricto de democracia representativa ${ }^{32}$. No había, en suma, espacio para preocuparse excesivamente por la legitimidad democrática de la Administración ${ }^{33}$.

Con el correr del tiempo, devino evidente que la Administración no se limita a aplicar mecánicamente lo que el parlamento le dicta ${ }^{34}$. De hecho, la complejidad, heterogeneidad y ambición de las tareas que el Estado persigue atender en la sociedad contemporánea impiden que el legislador pueda prefigurarlo todo, anticiparse a la realidad. En definitiva, cualquier intento de predeterminar por completo por parte del legislador la acción administrativa no es sino una utopía ${ }^{35}$ : en tantos ámbitos la ley no puede contener la receta para cada caso concreto o problema singular, como tampoco todas las opciones políticas posibles que quepa elegir ${ }^{36}$.

31 Son expresión, no ya solo del principio del Estado de derecho, sino también del principio democrático, elementos tan básicos como la primacía de la ley, la reserva de ley, y el principio de legalidad (vinculación de la Administración a la ley y al derecho); o la predeterminación o programación normativa de la Administración). Véase Eberhard SchmidT-Assmann, La teoría general del derecho administrativo como sistema, óp. cit., capítulo segundo, núm. 84.

32 Hans HeinRich Trute, óp. cit., p. 344.

33 Resta aún mucho recorrido para que los manuales y tratados tradicionales se ocupen con más profundidad, y en forma paralela al principio del Estado de derecho, del principio democrático en general y de la legitimidad democrática de la Administración en particular. Esta crítica se hace extensiva, aunque en medida desigual, a ambas tradiciones, la del civil law, con sus variantes también, y la del common law.

34 De nuevo el ejemplo de un banco central resulta paradigmático, pero también otros más clásicos como la creación de ciudad que a los municipios tienen atribuida.

35 Hans HeinRich Trute, óp. cit., p. 344

36 Para el derecho administrativo estadounidense fue este un hallazgo mucho más temprano, puesto que se ha admitido con más naturalidad que una agencia puede desarrollar 


\subsection{LA SINGULARIDAD DE LA ADMINISTRACIÓN}

No constituye ello necesariamente, sin embargo, una desviación del sistema, como pudiera pensarse desde el modelo teórico heredado del Estado liberal. Téngase en cuenta que las constituciones contemporáneas le atribuyen a cada uno de los poderes -también al Ejecutivo y a la Administración- una función singular específica. Y la Administración la tiene. Así, a la Administración se le reconoce una cierta capacidad de conformación o de configuración autónoma, más allá de la ejecución de las leyes. La Administración posee un ámbito propio de responsabilidad $-\mathrm{y}$ de prestación-que atender, naturalmente en el marco de la ley y el derecho ${ }^{37}$.

\section{PROCEDIMIENTOS ADMINISTRATIVOS PARTICIPATIVOS ANTE ADMINISTRACIONES "AUTOPROGRAMABLES"}

De entre las distintas clases de procedimientos administrativos nos interesan a nuestro efecto aquellos en los que la Administración despliega extensas potestades y en donde la ley no le marca la concreta solución a adoptar. En particular, se trata de procedimientos que reúnen dos notas: la primera es que su objeto sea propiamente crear derecho (reglamentos y normas infralegales de toda clase, planes, programas, elaboración de un anteproyecto de ley, etc.) o innovar el ordenamiento jurídico en sentido amplio (desde actos jurídicos de carácter constitutivo, como una licencia ambiental integrada; hasta la elaboración de un informe de impacto ambiental, por ejemplo). La segunda se resuelve en que la participación pública se erija en su nota distintiva ${ }^{38}$.

Esa clase de procedimientos de última generación se diferencia de aquellos otros, más tradicionales, cuyo objeto no se localiza en la creación, sino en la aplicación, del derecho (para el dictado, por ejemplo, de una autorización

sucesivamente políticas distintas sin necesidad de cambios legislativos. De ahí que se les haya exigido a las agencias que expliciten y motiven cuál es la opción política en que se funda su acción.

37 Constituye una aportación de la doctrina alemana relativa a la "reforma del derecho administrativo" (llamada también, no sin cierta exageración, aunque con pretensiones didácticas, "nuevo derecho administrativo") y subrayar la "autonomía" e "identidad propia" de la Administración. Para entender en su debido contexto este postulado, cabe remitirnos en español a EBERHARD SCHMIDT-AsSMAnN, La teoría general del derecho administrativo como sistema, óp. cit., capítulo cuarto y, también, segundo. En alemán, por todos, EBERHARD SCHMidTAssmann y Wolfang Hoffman-RiEM, §10, "Eigenständigkeit der Verwaltung", en Grundlagen des Verwaltungsrecbts, Grundlagen des Verwaltungsrechts, t. II, 2. ${ }^{a}$ ed., München: Beck, 2012.

38 Hallamos, pues, procedimientos que no son meramente "ejecutivos" o de aplicación del ordenamiento (como el sancionatorio), y procedimientos más participativos que los tradicionales. La Administración que aquí opera no es meramente "ejecutante", sino "autoprogramable" y en esa "autoprogramación" la participación adquiere una relevancia singular. 
reglada o la imposición de una sanción), o bien, aun siendo creativos (como lo es un plan urbanístico), no están abiertos a una participación intensa.

No pretende hacerse con ello una diferencia o clasificación pura y absoluta. Pero sí quiere destacarse que el procedimiento ocupa una posición distinta en cada caso, y requiere en consecuencia de un enfoque jurídico también diverso.

\section{LA PLURALIDAD DE LAS FORMAS Y FINES DE LA PARTICIPACIÓN}

Conviene notar que la participación no constituye un concepto jurídico, menos aún de carácter monolítico o unitario, sino un fenómeno plural, que adopta multitud de formas organizativas y procedimentales, y sirve a una variedad de fines.

En efecto, baste notar, con una rápida mirada al derecho positivo, que la participación puede darse en múltiples plantas o niveles de poder (local, regional, estatal, supraestatal y global $)^{39} y$, por tanto, dentro y fuera de las fronteras nacionales. Puede tener lugar ante organizaciones públicas (Administraciones) o privadas (asociaciones profesionales o de establecimiento de estándares, por ejemplo). Puede extenderse, más allá de los directamente afectados, al público en general y a otras Administraciones, incluidas las transfronterizas. Puede tener por objeto variadas finalidades (desde la defensa de los derechos e intereses de los afectados, pasando por la aportación de la información que la Administración necesita para organizar un sector, o la generación de consenso, hasta el control de la Administración por parte del público). Puede canalizarse a través de los más variados modos (por medio de consultas o alegaciones, audiencias o informaciones públicas, o mediante la presencia permanente de los representantes de los distintos grupos o colectivos en los órganos decisorios, como observador sin voto, o con él, por ejemplo). Puede presentar carácter vinculante o consultivo. Y así sucesivamente.

\section{CONDICIONES PARA QUE PUEDA HABLARSE \\ DE UNA MAYOR LEGITIMIDAD DEMOCRÁTICA \\ A CONSECUENCIA DE LA PARTICIPACIÓN \\ EN EL PROCEDIMIENTO ADMINISTRATIVO}

La participación es, pues, un fenómeno poliédrico, que no es susceptible de un tratamiento uniforme. A nuestros efectos, importa reflexionar sobre aquellas formas de participación que, sin ser expresión de la democracia directa, puedan transmitir una mayor legitimidad democrática a la Administración.

39 La escala importa. En el medio ambiente, por ejemplo, no es lo mismo decidir si se otorga o no una licencia ambiental integrada a nivel regional, que resolver sobre la apertura de una granja a nivel local, o la participación en un programa o plan con efectos estructurales sobre el medio ambiente en un espacio transfronterizo a nivel nacional y supraestatal. 


\subsection{LA PERSPECTIVA CLÁSICA DEL PRINCIPIO DEMOCRÁTICO}

De acuerdo con la concepción tradicional del principio democrático, la soberanía nacional reside en el pueblo, del que emanan todos los poderes del Estado $^{40}$. La voluntad popular no admite la fragmentación o troceamiento de esa voluntad popular en razón de territorio, de la materia o de los intereses concernidos. Es el pueblo en su conjunto y generalidad indiferenciada el que transmite la legitimidad democrática, y no un grupo de interesados o de afectados por una decisión ${ }^{41}$. Ello supone que no pocas formas de participación que se dan en numerosos procedimientos administrativos se sitúen cuando menos en una zona gris desde la perspectiva del principio democrático ${ }^{42}$, si no muy alejadas de este. Así, la mera participación de los interesados, no del pueblo, en un procedimiento de elaboración de disposiciones generales, a través por ejemplo de la información pública, no hace de su aprobación definitiva un "producto" más democrático. Y aunque la misma Constitución reconozca ciertas áreas o formas de participación ciudadana para la defensa de sus propios intereses ${ }^{43}$, ello en nada cambia o afecta a la premisa sobre la que se asienta el modelo democrático tradicional, ya que esas decisiones carecen de la legitimidad personal y material ${ }^{44}$. Es más, el principio democrático obliga a poner

40 Por ejemplo, artículo 1.2 de C.E. y artículos 1.2 y 20 de la Ley Fundamental alemana.

41 Esta última podrá ser una exigencia del principio del Estado de derecho, que obliga a dar audiencia a los interesados, pero no es expresión del principio democrático. Así, la doctrina y jurisprudencia dominantes. Para el caso alemán, por ejemplo, Hans HeinRich Trute, óp. cit., núm. marg. 54; EBERHARD SCHMIDT-ASSMANN, La teoría general del derecho administrativo como sistema, óp. cit., capítulo cuarto y segundo, núm. 81. El sujeto legitimador es el pueblo entendido como el conjunto de personas, sin disecciones en virtud de criterios de grupo o de interés. Se trata de una generalidad "abierta" y en ese sentido indiferenciada (EBERHARD SCHMiDT-ASSMANN, ibíd., y bibliografía allí citada).

42 Así, Eberhard Schmidt-Assmann, "Verwaltungslegitimation als Rechtsbegriff", Archio des öffentlichen Recbts, n. ${ }^{\circ}$ 116, Heidelberg: Mohr Siebeck, 1991, pp. 329 y ss.

43 Por ejemplo, artículo 105.a de la Constitución española: "La ley regulará: a) La audiencia de los ciudadanos, directamente o a través de las organizaciones y asociaciones reconocidas por la ley, en el procedimiento de elaboración de las disposiciones administrativas que les afecten". Por su parte, el artículo 11.1 TCE dispone: "Las instituciones darán a los ciudadanos y a las asociaciones representativas, por los cauces apropiados, la posibilidad de expresar e intercambiar públicamente sus opiniones en todos los ámbitos de actuación de la Unión". Y el artículo 10.3 TCE previamente establece que "Todo ciudadano tiene derecho a participar en la vida democrática de la Unión. Las decisiones serán tomadas de la forma más abierta y próxima posible a los ciudadanos".

44 Cfr. Hans Heinrich Trute, óp. cit., núm. marg. 54. Sobre el sentido de la legitimación personal y material, véase en español EBERHARD SCHMIDT-AsSMANN, La teoría general del derecho administrativo como sistema, óp. cit., capítulo segundo. 
en su debido contexto y distancia lo que a los intereses particulares - de un determinado colectivo- convenga ${ }^{45}$.

El punto de partida resulta, pues, restrictivo: la participación en un procedimiento administrativo no transmite per se y sin más una mayor legitimidad democrática a la Administración.

Con todo, cabe preguntarse si en determinadas condiciones una amplia y efectiva participación podría compensar el déficit que desde el punto de vista de su contenido material presentan tantas leyes ${ }^{46} \mathrm{y}$, en consecuencia y a la postre, si ello aporta mayor legitimidad material a la Administración por medio del procedimiento. Dicho de otro modo: cuando el parlamento le encarga a la Administración que complete desde dentro, a través del procedimiento, el fondo del asunto ¿sale fortalecida la legitimidad democrática de la Administración, si ese contenido legislativo se completa mediante una amplia participación procedimental?

\subsection{Condiciones PARA QUE PUEDA Hablarse}

DE "LEGITIMACIÓN (DEMOCRÁTICA DE LA ACCIÓN ADMINISTRATIVA)

A TRAVÉS DEL PROCEDIMIENTO ${ }^{\prime 47}$

A nuestro juicio, para que pueda decirse que la solución encontrada a través de los procedimientos administrativos de amplia participación está dotada de una mayor legitimidad democrática material o, lo que es lo mismo, que el procedimiento complementa la legitimidad de la decisión de fondo que se adopte ${ }^{48}$, han de darse ciertas condiciones elementales, unos presupuestos básicos, íntimamente

Sobre la necesidad de esa "distancia democrática" en que han de contemplarse los intereses de grupo o de colectivos determinados, véase EBERHARD SCHMidT-AsSmann, La teoría general del derecho administrativo como sistema, óp. cit., capítulo segundo, núm. marg. 81. Cuando la participación remite al círculo de interesados o afectados no cabe conectar con la colectividad indiferenciada, con el pueblo, cfr. Hans HeinRICH TRUTE, óp. cit., núm. marg. 47.

46 Eberhard SChmidt-Assmann, La teoría general del derecho administrativo como sistema, óp. cit., capítulo segundo, núm. marg. 111; ElKe GuRLIT, "Der Eigenwert des Verfahrens im Verwaltungsrecht", Veröffentlichungen der Vereinigung der Deutschen Staatsrechtslebrer, n. ${ }^{\circ} 70$, Berlin: De Gruyter, 2011, p. 242.

47 Aludimos aquí a la denominada "legitimación democrática de la Administración" y, más en concreto, a la legitimación que llamamos "material" o "interna". Sobre este punto, véase EBERHARD SCHMIDT-AsSMANn, La teoría general del derecho administrativo como sistema, óp. cit., capítulo segundo, núm. 82 y ss. Recuérdese que la legitimación democrática de carácter interno o material se transmite mediante la vinculación del Ejecutivo y de la Administración a la ley parlamentaria, a su contenido y voluntad. Ello quiere decir, en otras palabras, que el principio de legalidad no es solo una exigencia del principio del Estado de derecho, sino también del principio democrático.

48 Se trata de una de las vías o medios de legitimación de acuerdo con la concepción clásica, la legitimidad denominada de carácter interno o material. Para conocer el estado de la cuestión y los problemas contemporáneos relacionados con el principio democrático y Administración pública, véase, en español, EBerhard SCHMidT-AsSmann, La teoría general 
relacionados, que podrían diseccionarse para su consideración y análisis del siguiente modo:

a. En primer lugar, el legislador debe de establecer un procedimiento ampliamente participativo que sirva para "rellenar" el contenido material que la ley deja abierto. Es la ley democrática la que resuelve acudir a una específica -y amplia- participación en el seno del procedimiento administrativo. A través de este se continúa, concreta y cierra el proceso volitivo, iniciado por la ley, y diferido para su completud a la Administración. La participación aquí, pues, tiene por objeto colmar el contenido material e interno de la ley y, en ese sentido, la voluntad democrática expresada en el parlamento ${ }^{49}$. El procedimiento administrativo ha de ser estructurado a tal efecto, de modo que pueda responder a esa función legitimadora ${ }^{50}$, aun cuando, como sucede con frecuencia, la participación pueda atender a un tiempo otras finalidades ${ }^{51}$. En suma, el procedimiento que el legislador establece ha de servir para desarrollar la previsión legal.

del derecho administrativo como sistema, óp. cit., capítulo segundo. En alemán, con mayor abundamiento, Hans HeinRich TRUTE, óp. cit., pp. 341 y ss.

49 Por ejemplo, el derecho urbanístico podría establecer amplias fórmulas participativas que tengan por objeto concretar cómo y por dónde ha de crecer la ciudad, rellenando así el espacio que la legislación haya dejado.

50 No valdría, en el caso de la nota anterior, el modelo de "información pública", por estrecho e insuficiente a efectos de la legitimación democrática (no así para las exigencias del principio del Estado de derecho).

51 Más allá de esta función genuinamente democratizadora -en cuanto continuadora del contenido material de la ley-, la apertura de la participación en el seno de los procedimientos decisorios puede responder a una multitud de objetivos y estrategias distintas y no excluyentes. Así, por ejemplo, puede perseguir que la población se sienta involucrada y responsable activa de determinadas políticas públicas, como sucede en el ámbito del medio ambiente. En otras ocasiones, se pretende con ello generar el máximo consenso y aceptación por parte de los destinatarios, de modo que estos puedan intervenir en el debate antes de que la medida se apruebe. Igualmente, la participación puede obedecer a la necesidad de obtener y procesar la mejor información disponible en manos del sector privado (industrias de toda clase, por ejemplo), al objeto de adoptar finalmente la decisión que corresponda sobre una base suficiente. En este contexto, conviene recordar asimismo el "efecto acordeón" que, de algún modo, siempre cumple el procedimiento administrativo: de un lado, una ley de procedimiento sirve para que el parlamento dirija y controle a la Administración (aunque aquel no puede saber qué decisión esta podrá tomar en el futuro en tantos casos, sí puede determinar cómo habrá de tomar esa decisión, lo cual no es poco, puesto que supone una suerte de "decisión sobre la decisión"); de otro, una ley de procedimiento permite que el ciudadano controle a su vez si la Administración observa o no las reglas y formas establecidas para decidir, accionando en su caso ante los jueces.

Ciertamente, esas y otras funciones adicionales y no excluyentes pueden de un modo mediato entroncar con el principio democrático. Por ejemplo, en una democracia, cabe admitir que no basta con que la decisión que adopten el Ejecutivo y la Administración sean correctas, esto es, legales, sino que además han de ser convincentes. Ahora bien, que la medida a adoptar se presente de modo que genere mayor o menor capacidad para convencer, no le añade por sí misma, de modo directo, una mayor legitimidad democrática. 
b. En segundo término, la participación ba de ser suficientemente representativa e inclusiva:

- Primero, por el número de participantes movilizados. Por ejemplo, una participación en manos de minorías activas, nucleadas en torno a partidos o movimientos de escasa representatividad, o de entidades públicas o privadas interesadas con un fuerte músculo participativo, no sería una participación representativa, puesto que la participación quedaría reducida o capturada por una minoría.

- Segundo, por los sectores, ámbitos e intereses involucrados en cada caso. La participación ha de dar paso a todas las perspectivas (interesados, público interesado, público en general, así como en su caso a expertos y a otras Administraciones). La participación que solo recogiera intereses sectoriales o especiales, por definición fragmentados e incompletos, esto es, que solo incorporase de hecho o de derecho a "su público" más directamente afectado, no es expresión de, ni guarda relación con, la democracia ${ }^{52}$. No se trata, pues, de una participación de tipo corporativo (como, por ejemplo, la que se limita a las organizaciones sindicales y empresariales), ni, tampoco, de una participación conforme al modelo de representación de intereses (centrado en los sectores, industrias, mercados o personas directamente afectados). La participación ha de estar abierta a todos los intereses y sectores.

- Tercero, por los niveles de gobierno implicados. La participación debe de incluir, según los casos, a otras plantas de gobierno (Administraciones superiores o inferiores, entidades locales, Administraciones transfronterizas), en la medida en que puedan verse involucradas siquiera sea mediatamente en sus respectivas competencias ${ }^{53}$.

c. La participación ba de consistir y resolverse en una suerte de "conversación" o "diálogo". La Administración responsable, en efecto, debe de hacer posible un verdadero "diálogo", una "conversación" con los participantes, y de estos entre sí. Ello

Baste pensar que en esta clase de procedimientos se trata de ponderar y arbitrar complejos intereses encontrados de múltiples partes implicadas, de donde se deduce que ese carácter multilateral puede impedir el consenso. Lo mismo cabría sostener respecto de la motivación, de la que cabe decir que no es solo una derivada del Estado de derecho (que obliga a que toda decisión de un poder público sea racional y racionalizable, máxime cuando afecta a la esfera subjetiva del individuo), sino también del principio democrático (una autoridad sin argumentos es literalmente deshumanizadora y contraria a la dignidad humana). Sin embargo, la satisfacción de cualesquiera de estas finalidades (control, implicación ciudadana en políticas públicas, consenso y aceptación) no hace a nuestro juicio más democrática una decisión. La hará más eficaz y responsable.

52 En el sentido, claro está, de que esa participación parcial sea susceptible de otorgar una mayor legitimidad democrática. No quiere decirse, en cambio, que una tal participación sea contraria al principio democrático.

53 Por ejemplo, el procedimiento para adoptar una decisión municipal relevante (infraestructuras, urbanismo, medio ambiente) que afecte de un modo significativo a otros municipios, para ser representativa y conectar con la legitimidad democrática, habrá de facilitar la presencia de esas otras Administraciones involucradas. 
puede arbitrarse a través de múltiples técnicas y fórmulas, de una enorme plasticidad y capacidad de adaptación: transparencia y acceso a la información, preparación de consultas asequibles, por comprensibles, para la generalidad, sucesivas rondas de participación cuando sea necesario ${ }_{i}$ adecuada ponderación de las alegaciones vertidas y de la información generada a lo largo del procedimiento; motivación de la decisión que finalmente se adopte, entre otras. Accesibilidad (entendida también como comprensibilidad para todos), ponderación y motivación constituyen las claves de ese "diálogo".

Con estas tres notas, en otras palabras, quieren destacarse dos extremos:

Primero, la participación, como la democracia, no puede concebirse como una ficción normativa, sino como una realidad efectiva ${ }^{54}$. Ello exige una actitud proactiva de la propia Administración y colaborativa de los interlocutores y partícipes en su consecución.

Segundo, la participación -y con ella la motivada decisión final- dejan traslucir la centralidad del individuo en un Estado democrático, constituido en sujeto del derecho y no en objeto ${ }^{55}$. El diálogo de la Administración con el ciudadano responde a la concepción que subyace a la Constitución, de acuerdo con la cual este no es un ciudadano mudo, sino una persona dotada de dignidad, entendimiento este que se sitúa en la base del ordenamiento jurídico ${ }^{56}$.

Lo que hay detrás de esas condiciones, en suma, no es sino un postulado elemental, que hunde sus raíces en el principio democrático, a saber: la democracia representativa se ve enriquecida cuando la participación -en el procedimiento creativo- sirve de complemento y continuidad a lo dispuesto por la ley. Y esa participación, lejos de quedar atrapada por, o circunscrita a, un grupo determinado de interesados, resulta inclusiva de la generalidad y se

54 De "influencia constitutiva" o "influencia configuradora" o "creadora" ("gestaltende Einflußnabme") habla la doctrina alemana. Véase la referencia en EberHard SCHMidT-Assmann, La teoría general del derecho administrativo como sistema, óp. cit., capítulo segundo, núm. marg. 111.

55 En ese sentido, respecto de la motivación, véase JeRRY L. MASHAW, "Reasoned Administration: The European Union, the United States, and the Project of Democratic Governance", Faculty Scholarship Series, n. ${ }^{\circ} 1179$, New Haven: Yale University, 2007. Disponible en línea http://digitalcommons.law.yale.edu/fss_papers/1179. En términos más generales, sobre la cultura de la justificación, véase Moshe CoHen-Eliya e Iddo Porat, Proportionality and Constitutional Culture, Cambridge: Cambridge University Press, 2013, p. 129.

56 Así, desde 1977, la jurisprudencia del Tribunal Constitucional Federal alemán. Cfr. BVerfGE 45, 297 (335); Apud EBERHARD SCHMIDT-AsSMANn, La teoría general del derecho administrativo como sistema, óp. cit., capítulo segundo, núm. marg. 111. Como recuerda el artículo 10.1 C.E., la dignidad de la persona, los derechos inviolables que le son inherentes, el libre desarrollo de la personalidad, el respeto a la ley y a los derechos de los demás son fundamento del orden político y de la paz social. 
caracteriza por su naturaleza deliberativa ${ }^{57}$, y por su apertura a la posibilidad de influir realmente sobre el resultado ${ }^{58}$.

Si se dan esas condiciones puede hablarse, a nuestro juicio, de verdadera y propia "legitimación a través del procedimiento", entendida esta como complemento de la democracia parlamentaria o representativa. Es decir, podrá afirmarse que se transmite la voluntad popular a través del procedimiento, concretando así el contenido material de la ley. Si, por el contrario, no concurren, el procedimiento no alcanzará el rango o grado necesario para servir de instrumento de legitimación democrática a la que aquí se hace referencia, aun cuando satisfaga otros objetivos e implique otros beneficios (y resulte en su caso más

57 La deliberación a la que aquí se hace referencia, en el plano administrativo, ha de ser en verdad inclusiva. Por hipótesis, un procedimiento podría ser deliberativo -en la medida en que pondere cuidadosamente todas las alegaciones y argumentos esgrimidos por el público interesado- $y$, sin embargo, no resultar inclusivo, ni, en consecuencia, suficientemente ponderado, por haber tenido en cuenta solo a "su" público, pero no a todos los afectados, menos aún al público en general cuando proceda. Y es que la participación en el procedimiento, para ser incluyente, no ha de ser solo "interna" o "hacia adentro", sino que en tantas ocasiones ha de mirar también hacia el "exterior", "hacia fuera". Así, por ejemplo, la participación en la elaboración de un plan de estudios de una universidad pública no será deliberativa, aunque se haya practicado la deliberación y seguido un verdadero y constructivo debate en su seno, entre todos los estamentos que la integran, ni siquiera aunque haya conseguido un deseable consenso interno, si no participan los "de fuera": el sector profesional que va a verse directamente afectado por el ejercicio profesional derivable del título obtenido con ese plan de estudios; los expertos sobre empleabilidad; o la perspectiva de otras universidades y Administraciones interesadas, entre otros.

Ello significa que el debate o deliberación no ha de ser el resultado aleatorio de quienes eventualmente comparezcan en un procedimiento dado, en una concreta organización. A nuestro juicio, es necesario adoptar una actitud activa, que va más allá de la oportuna publicidad y de la accesibilidad de la información necesaria, lo que no es poco para identificar cuando menos las principales posiciones enfrentadas y asegurar su participación. A título de ejemplo y como dispone el Convenio de Aarhus, el solicitante individual de una autorización en materia ambiental puede coadyuvar "a identificar al público afectado, a informarle del objeto de la solicitud que se propone presentar y a entablar el debate con él al respecto antes de presentar la solicitud" (artículo 6). Una universidad, en el ejemplo anterior, bien podría hacer lo propio a la hora de elaborar, modificar o reformar un plan de estudios. A toda organización reguladora responsable, por citar otro caso en el plano global, no le habría de resultar difícil tampoco determinar ex ante cuáles son los efectos contrarios que potencialmente pueden generar sus decisiones y cuáles son en consecuencia los intereses contrapuestos (por ejemplo, intereses ambientales o laborales, frente a los intereses comerciales y una mayor competitividad en favor de los consumidores y usuarios). La deliberación, para ser sincera, ha de comenzar por llamar -por "emplazar"- a aquellos que se sabe representan intereses o sectores distintos.

58 Lo cual no significa, por más que la línea de frontera en ciertos casos no sea fácilmente deslindable, que influencia equivalga a codecisión. 
que apreciable y necesaria) ${ }^{59}$. En todo caso, cabe admitir una graduación o escala, también en lo que hace a la "legitimación a través del procedimiento".

No es fácil, desde luego, que se den todas estas condiciones, aunque, como se verá de seguido, las últimas generaciones de procedimientos administrativos se mueven en esa dirección. Las fórmulas participativas dominantes en el pasado han quedado, en el mejor de los casos, en manos de los directamente afectados $y$, en consecuencia, aunque positivas por más de un concepto, en modo alguno pueden calificarse de "legitimadoras" en el sentido de otorgar, por sí mismas, un plus de legitimidad democrática.

\section{UN MUESTRARIO DE SUPUESTOS DE PARTICIPACIÓN PROCEDIMENTAL}

Los criterios apuntados en el epígrafe precedente deben de contrastarse a través de una muestra de procedimientos administrativos. A ello nos dedicamos seguidamente.

Sin pretensiones conceptuales y a efectos expositivos, baste una simple selección basada en la razonable distinción entre procedimientos que aquí denominamos "tradicionales", y en los que los canales de participación se hallan limitados en el espacio y en el tiempo (7.1), de un lado, y, de otro, aquellos que calificamos de "amplia participación" $(7.2)^{60}$. A este propósito, se toman algunas referencias normativas del ordenamiento jurídico español -de modo implícito o explícito- con fines puramente didácticos.

\subsection{LA PARTICIPACIÓN EN PROCEDIMIENTOS ADMINISTRATIVOS TRADICIONALES}

Piénsese de entrada en los siguientes ejemplos: la participación en un órgano colegiado de una universidad pública para debatir sobre la organización de las clases y su horario (7.1.1); la participación en un procedimiento administrativo

59 Por ejemplo, la generación de consenso y la aceptación de la acción administrativa constituyen un evidente desiderátum. Para algunos autores, conectan estos objetivos con el principio democrático. Lo cierto es que cualquiera puede discrepar de una política pública en un espacio y tiempo determinados -medio ambiente, urbanismo, educación, etc.-, y, desde luego, no estar de acuerdo con tantas normas y resoluciones singulares al servicio de esas políticas. Y, así y todo, es posible que las acepte de buen grado, si ha tenido ocasión de ser parte, si ha existido debate, se han escuchado las razones en favor o en contra, se ha expresado una ponderación de los distintos intereses enfrentados, en definitiva, si ha habido una participación real y efectiva y, por ello también, una adecuada justificación de las medidas adoptadas.

60 Para una breve introducción sobre el tema, me remito a mi trabajo "Introducción. Reforma e innovación del procedimiento administrativo", en La transformación del procedimiento administrativo, Sevilla: Global Law Press - Editorial Derecho Global, 2008, pp. 19 y ss.; 63 y ss. 
en el que se solicita una autorización o permiso (7.1.2); y la participación en la elaboración de un plan, programa o reglamento (7.1.3).

\subsubsection{Participación en los órganos colegiados de gobierno de la universidad}

La participación en el seno de un órgano colegiado de la universidad-para la organización de las clases, por ejemplo- representa un supuesto de mera autogestión. Ninguno de los miembros de ese órgano (profesores, estudiantes, personal de administración) ha sido elegido directa o indirectamente por el pueblo. No cabe hablar, en ese sentido, de legitimidad en el plano personal (no hay conexión alguna entre la persona y el pueblo). En modo alguno sus decisiones se adoptan en nombre del pueblo o le son en última instancia atribuibles, ni se rinden cuentas ante este. Por otro lado, la participación se halla limitada a los miembros de esa organización y ninguna influencia directa tienen otros colectivos externos o ajenos a la universidad potencialmente interesados (profesionales, artísticos, científicos, empresariales), ni el público en general. Esa participación no dota de mayor legitimidad democrática a la decisión que se adopte. Hablamos en cambio de una legitimidad funcional, atribuida por el legislador, para la satisfacción de fines específicos ${ }^{61}$, $\operatorname{cosa}$ bien distinta.

\subsubsection{La participación en un procedimiento administrativo autorizatorio tradicional o sancionatorio}

La participación en un procedimiento autorizatorio, por ejemplo, podría darse por un doble concepto o condición: como solicitante que inicia el procedimiento e interesa un permiso, o como tercero que comparece para oponerse o alegar lo que a sus intereses y derechos convenga. En cuanto solicitante, el interesado podrá participar en diversos momentos (apertura, instrucción y terminación convencional, entre otros). Así, en la fase de instrucción, su participación se resuelve en el ejercicio de sus derechos de defensa (prueba, audiencia del interesado). Como tercero - por ejemplo, en materia medioambiental- un individuo puede participar para invocar sus propios derechos y oponerse a la pretensión del solicitante.

El principio democrático tampoco está presente en estos casos ${ }_{i}$ los participantes persiguen la consecución y defensa de sus propios derechos e intereses $^{62}$. Aquí, la participación no está enderezada a fortalecer la legitimidad democrática de la organización que decide y resuelve. Es el principio del

61 Véase aparte 7

62 Por otra parte, la Administración no crea propiamente derecho, sino que lo aplica, no siendo apreciable su margen de maniobra o interpretación. 
Estado de derecho -derechos de defensa, audiencia del interesado, defensa de los propios derechos e intereses- el que ofrece soporte a la participación ${ }^{63}$.

\subsubsection{La participación en procedimientos administrativos de elaboración de disposiciones generales al modo tradicional}

En el ordenamiento español, por contraste con el panorama comparado, goza de una larga tradición la participación de los interesados, señaladamente a través de asociaciones representativas, en la elaboración de disposiciones generales (lo que es susceptible de incluir no solo los reglamentos, sino la preparación de los anteproyectos de ley). Así, por ejemplo, cabe citar en esa dirección la Ley de Procedimiento Administrativo de $1958^{[64]}$, los procedimientos de elaboración de las ordenanzas locales ${ }^{65}$ y otras leyes sectoriales ${ }^{66}$.

En estos procedimientos, la participación se contrae a un momento puntual -no acompaña a toda la gestación de la norma- y se sitúa, no en una fase temprana, cuando las opciones de influir son mayores, sino en un momento final, cuando la norma está ya "cocinada". Es el caso, por ejemplo, de los reglamentos ejecutivos. El clásico trámite de la "información pública"67, mediante el que se expone al público el proyecto normativo ya formado en su integridad antes de su inmediata aprobación, resulta ilustrativo y constituye una clásica modalidad participativa en el marco de este modelo. La razón de

63 Y se trata, por lo demás, de un procedimiento administrativo construido, con las adaptaciones necesarias, a imagen y semejanza del proceso judicial, y al que se accede en virtud de la legitimación que se ostente.

64 Artículos 129 y ss. Por su parte, en el artículo 105.a de la Constitución de 1978 ("La audiencia de los ciudadanos, directamente o a través de las organizaciones y asociaciones reconocidas por la ley, en el procedimiento de elaboración de las disposiciones administrativas que les afecten") parece estar pensando en esta clase de participación (puntual y tardía), aunque ese mismo precepto no impide en modo alguno una participación extensa.

65 Por ejemplo, artículo 49 de la Ley 7/1985, del 2 de abril, Reguladora de las Bases del Régimen Local, en el que se dispone la aprobación inicial de la ordenanza local, a la que le sigue el trámite de información pública.

66 La legislación urbanística tradicional, por ejemplo, apostaba por una participación en una fase tardía en la elaboración de los planes. Así, el Real Decreto 2159/1978, del 23 de junio por el que se aprueba el Reglamento de Planeamiento para el desarrollo y aplicación de la Ley sobre Régimen del Suelo y Ordenación Urbana, en sus artículos 38, 85, 96 y 97, que concibe la participación como un "trámite" de información pública.

67 Cuando menos, la legislación tradicional, en particular la de procedimiento administrativo (así, las leyes de 1958 y la Ley 39/2015; o su equivalente respecto de la Ley 30/1992, la 50/1997 del Gobierno) no establecen obligación legal de ponderar y motivar la decisión finalmente adoptada una vez evacuado el trámite de información pública, si bien cabría derivar el deber de motivar a partir de principios generales y valores que la Constitución reconoce, como el principio del Estado de derecho, en cuya virtud toda decisión ha de ser racional y racionalizable. 
ser de la información pública parece residir fundamentalmente en la defensa de los derechos e intereses, con frecuencia de carácter difuso o colectivo ${ }^{68}$.

No parece desde luego que esta forma de participación pueda constituir una expresión del principio democrático, no ya solo por su finalidad defensiva, sino también por su (consecuente) limitación temporal, al estar referida al momento final, ${ }_{i}$ por su alcance subjetivo, circunscrito a un colectivo determinado y con escasas posibilidades reales de influencia. Ciertamente, ese esquema -participación acotada en el tiempo y en el espacio- resulta coherente a la postre con la premisa de partida: si de lo que se trata es de evitar la aprobación de una norma sin haber oído a los intereses representativos, basta con la información pública. Y en caso de que estos se vean afectados de modo ilegítimo o inconveniente, habrá ocasión, evacuado ese trámite, de introducir la modificación puntual que proceda. Carece de sentido, desde ese prisma, una participación más inclusiva (que incorpore a los que no se vean afectados por la medida) o extensa (ya sea en términos materiales o temporales).

\subsection{Procedimientos administrativos de Amplia PARTicipación}

Nos referimos en este epígrafe -a nuestro limitado propósito- a procedimientos administrativos que reúnen esas dos notas que nos resultan ya conocidas: primero, procedimientos que no son meramente aplicativos, sino creativos o innovadores, dotados de un notable espacio para la creatividad y la innovación ${ }^{69}$; $y$, segundo, procedimientos de amplia participación, de una cierta complejidad en la medida en que puede intervenir una constelación de actores, y donde la decisión final no emana sin más y en cascada desde un centro superior, esto es, de procedimientos que no se estructuran exclusivamente en torno al principio de jerarquía ${ }^{70}$.

68 Así parece entenderlo el artículo 133.2 de la Ley 39/2015, de Procedimiento Administrativo. En igual sentido, se pronunciaba el artículo 26.6 de la Ley 50/1997, del Gobierno.

69 Ese margen de apreciación atribuido por el legislador a la Administración, en ocasiones muy superior a la clásica escala de la discrecionalidad administrativa, como sucede en los ejemplos antes citados, puede darse, primero, a consecuencia de la incapacidad de la ley para anticiparse a la realidad y dirigir cuál haya de ser la acción administrativa (cómo y por dónde haya de crecer la ciudad; si procede, y en qué términos, otorgar una licencia ambiental integrada; si ha de intervenirse un banco; etc.) $)_{i}$, también, en segundo lugar, cuando el legislador prefiere dejar los detalles al consenso técnico y/o político mediante un procedimiento deliberativo, como sucede en cierto modo y en ciertos casos en la implementación de los actos jurídicos de la Unión Europea a través de la comitología.

70 Por ejemplo, la elaboración de planes, programas y normas infralegales de toda clase y

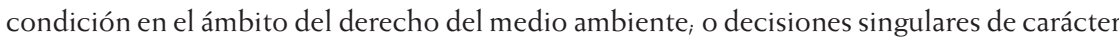
innovador, como puede ser una licencia o autorización ambiental. No siempre será un acto jurídico normativo el objeto de esta clase de procedimientos. Puede ser un acto administrativo, como una evaluación ambiental o de impacto regulatorio; o la preparación de 
Cabe señalar respecto de esta modalidad de participación una doble circunstancia: que su objeto propio ya no se detiene en la defensa de los propios derechos e intereses, sino que se extiende a cualquier otra consideración de conveniencia u oportunidad ${ }_{i}$ y que no se limita a un único y tardío momento, sino que acompaña el entero ciclo de la vida del acto jurídico: preparación, aprobación y ejecución ${ }^{71}$.

En otras palabras, esta participación, cuando menos tendencialmente, está abierta a otros sujetos o actores más allá de los directamente afectados; resulta extensa, en cuanto a su proyección en el espacio y en el tiempo y a los temas que abarca ${ }_{i}$ y es deliberativa, por el debate y diálogo que propicia. Esas tres características podrían también sintetizarse en la idea de colaboración ${ }^{72}$.

Veámoslo más despacio a través de algunos ejemplos.

\subsubsection{El caso de la participación en el derecho del medio ambiente}

El medio ambiente representa un ámbito ilustrativo, aunque no perfecto, de esta clase de participación en procedimientos administrativos decisorios de carácter creativo o innovador. Así, por ejemplo, el Convenio de Aarhus -Convenio $\mathrm{UNCE}^{73}$-, en sus artículos 6 a 8 , dispone una extensa participación del público en asuntos medioambientales, concebida como un derecho (artículo 1), bien sea cuando se trate de adoptar decisiones relativas a actividades particulares (artículo 6), de aprobar planes, programas y políticas públicas (artículo 7), o de elaborar disposiciones reglamentarias o de instrumentos normativos jurídicamente obligatorios de aplicación general (artículo 8). Se trata de una participación que se regula -escalonadamente- en función del objeto sobre el que recae (acto administrativo, planes y programas, normas). La participación en el procedimiento decisorio tiende hacia una cierta plenitud, apertura y deliberación. Así, por ejemplo, y de manera simplificada a nuestros efectos ${ }^{74}$ :

un relevante contrato de servicio público para la recogida y el tratamiento de basuras de toda una región, por ejemplo. No es el modelo judicial el que sirve de inspiración.

71 Esto es, abarca la preparación, elaboración y ejecución. Así, el artículo 133.1 de la Ley 39/2015, de Procedimiento Administrativo, prescribe que "con carácter previo a la elaboración del proyecto o anteproyecto de ley o de reglamento, se sustanciará una consulta pública". Como puede suceder, también, con un instrumento o plan urbanístico (artículo 5.e del Real Decreto Legislativo 7/2015, de 30 de octubre, por el que se aprueba el texto refundido de la Ley de Suelo y Rehabilitación Urbana).

72 Aquí con el término "colaboración" no se alude a una cooperación voluntaria y libre, sino a la necesaria participación de distintos sujetos.

73 Convention on Access to Information, Public Participation in Decision-Making and Access to Justice in Environmental Matters, aprobado el 25 de junio de 1998, que pretende poner en práctica y de modo jurídicamente vinculante lo dispuesto en el principio 10 de la Declaración de Río.

74 No es necesario notar que los ejemplos que a estas páginas se traen sirven a la exposición principal, y no se erigen en el centro del trabajo. Así, y respecto del Convenio que ahora 
- En cuanto al sujeto facilitador, están obligados a garantizar la participación en los procedimientos decisorios no solo (todas) las Administraciones públicas con responsabilidades medioambientales, sino también los actores privados que ejerzan funciones materialmente administrativas, en particular tareas, actividades o servicios particulares relacionados con el medio ambiente ${ }^{75}$, así como los actores privados que asuman responsabilidades o funciones públicas o presten servicios públicos relacionados con el medio ambiente al servicio de los dos anteriores (Administraciones y agentes privados) ${ }^{76}$.

- En lo que hace al sujeto con derecho a participar ${ }^{77}$, se incluye no solo el público interesado -es decir, el que puede resultar afectado por las decisiones adoptadas en materia ambiental o que tiene un interés que invocar en la toma de decisiones-, sino también el público en general, cuando se trata de actos de alcance general ${ }^{78}$.

- El ciclo temporal de la participación comprende, cuando menos respecto de ciertos actos jurídicos ${ }^{79}$, todas las fases o etapas, desde las más tempranas "al inicio del procedimiento, es decir, cuando todas las opciones y soluciones son aún posibles y cuando el público puede ejercer una influencia real ${ }^{180}$, hasta la ejecución ${ }^{81}$.

- Los resultados de la participación en el procedimiento habrán de tenerse debidamente en cuenta ${ }^{82} \mathrm{O}$, en otros casos, se tendrán en consideración todo lo posible ${ }^{83}$. La autoridad responsable, y es lo que interesa finalmente retener,

se examina, ha sido desarrollado no solo a nivel internacional, sino dentro de la Unión Europea. Los detalles quedan fuera de nuestra consideración.

75 Cfr. artículo 2.2.b del Convenio. Por su parte, la Ley española 27/2006, del 18 de julio, por la que se regulan los derechos de acceso a la información, de participación pública y de acceso a la justicia en materia de medio ambiente (incorpora las directivas 2003/4/ CE y 2003/35/CE) establece en ese sentido: "Tendrán la condición de autoridad pública, a los solos efectos de lo previsto en los Títulos I y II de esta Ley, las personas físicas o jurídicas cuando asuman responsabilidades públicas, ejerzan funciones públicas o presten servicios públicos relacionados con el medio ambiente bajo la autoridad de cualquiera de las entidades, órganos o instituciones previstos en el apartado anterior".

76 Cfr. artículo 2.2.c del Convenio. Tanto los sujetos públicos como los actores privados en determinados supuestos están obligados, pues, a dar cauce a la participación que corresponda en función del objeto (acto, política o norma).

77 El Convenio distingue entre los distintos actos jurídicos en sus artículos 6-8, entre público interesado (artículo 6) y público en general (artículos 7 y 8 ). El Convenio distingue entre "the public" y "the public concerned" en su artículo 2 (definitions), apartados 4 y 5. La interpretación ulterior ha sido, a nuestro juicio, restrictiva en la legislación (en favor de "the public concerned"). Estas cuestiones quedan fuera de nuestra consideración.

78 Cfr. artículos 2.4 y 2.5, 6.2, 7 y 8 del Convenio.

79 La distinción de la participación en tres preceptos del Convenio (artículos 6, 7 y 8), en función del acto jurídico o del objeto de la participación, determina que el régimen de esta no sea uniforme. Todo ello queda fuera de nuestro examen.

80 Cfr. artículo 6.4 del Convenio.

81 Artículo 6.3 in fine del Convenio; implícitamente, artículo 6.10.

82 Artículos 6.8 y 7.

83 Artículo 8 in fine. 
habrá de ponderar todas las opiniones, alegaciones o información obtenida a través de los diversos canales de participación, y expresar el resultado de la ponderación a través de la correspondiente motivación ${ }^{84}$.

- Para garantizar que la participación sea real y efectiva, se establece el derecho de todos -y no solo de los interesados- a acceder a la información sobre el medio ambiente en poder de los "sujetos facilitadores" ${ }^{185}$, derecho este protegido a su vez mediante el derecho de acceso a la justicia para velar por su cumplimiento ${ }^{86}$. A tal fin sirven igualmente los deberes que pesan sobre la Administración de disponer, entre otras cosas, de la mejor información posible y actualizada en la materia; de establecer mecanismos de cooperación e intercambio de información entre las autoridades competentes; y de publicidad activa y de promoción de la accesibilidad de todos a la información en diversos formatos y modalidades (acceso electrónico, bases de datos, puntos de contacto, etc. ${ }^{87}$. A ellas se añaden otras garantías básicas, señaladamente respecto del dictado de actos administrativos singulares, como puede ser el caso de una licencia ambienta ${ }^{88}$. Para la efectividad de la participación, habrán de establecerse, en las diferentes fases del procedimiento, plazos razonables que dejen tiempo suficiente para informar al público y para que este se prepare y participe realmente en los trabajos a lo largo de todo el proceso ${ }^{89}$, incluida la fase de ejecución y eventual reforma del acto jurídico ${ }^{90}$. Y se dispone igualmente el contenido mínimo obligatorio de la información que ha de ponerse a disposición del público interesado ${ }^{91}$, así como un resumen que resulte comprensible para los no expertos ${ }^{92}$.

Con los matices que no son del $\operatorname{caso}^{93}$, la participación, en lo que ahora importa, resulta tendencialmente inclusiva, en cuanto a los sujetos (tanto de los facilitadores -los que tienen el deber de proveerla-, como de los que tienen

84 Aunque es un extremo que queda fuera de nuestro objeto, pues se trata tan solo de un ejemplo, es cierto que el Convenio solo estipula la motivación respecto de los actos singulares (artículo 6.9). El deber de motivar, sin embargo, cuando menos en los ordenamientos internos respecto de los demás actos jurídicos, cabría derivarlo de otros principios y tradiciones.

85 Artículo 4.

86 El artículo 9 garantiza el derecho a la información mediante el acceso más amplio posible a la justicia en asuntos ambientales (o ante un órgano independiente o imparcial).

87 Artículo 5.

88 Artículo 6.

89 Artículo 6.3

90 Apartados 9 y 10 del artículo 6.

91 Artículo 6.2 y 6.6.

92 Artículo 6.6.d.

93 Una de las cuestiones más críticas reside, a nuestro juicio, en que a pesar la amplitud del concepto de "público" la tendencia, permitida por el propio Convenio, a que cada Estado determine el colectivo afectado, termina por reducirlo al de "público afectado" o "interesado". 
derecho a participar); universal, en lo que a la materia concierne, por afectar en principio a todo asunto medioambiental ${ }_{i}$ integral, por lo que hace a su objeto, esto es, a los actos jurídicos que directa o indirectamente puedan aprobarse o verse involucrados (actos administrativos singulares y generales, evaluaciones e informes, normas de toda clase, programas, planes y políticas públicas, etc.); continuada, por extenderse al entero ciclo temporal, que va desde la preparación del acto jurídico en una etapa temprana, cuando las opciones están abiertas, hasta su aprobación y ejecución, comprendida asimismo su modificación o reforma ${ }_{i}$ y discursiva, en la medida en que la autoridad responsable ha de ponderar la información obtenida a través de la participación del público y expresarla en la motivación, entablando así una suerte de "diálogo".

Por su parte, la legislación de evaluación estratégica ambiental de planes y programas con efectos sobre el medio ambiente a nivel europeo extiende la participación a las Administraciones nacionales y a las Administraciones transfronterizas. Y es que, como afirma la legislación nacional en su desarro$1 \mathrm{lo}^{94}$, las Administraciones públicas habrán de

ajustar sus actuaciones en materia de evaluación ambiental a los principios de lealtad institucional, coordinación, información mutua, cooperación, colaboración y coherencia. A tal efecto, las consultas que deba realizar una Administración pública garantizarán la debida ponderación de la totalidad de los intereses públicos implicados y, en particular, la de aquéllos cuya gestión esté encomendada a otras Administraciones públicas.

Aunque el término "plan" o "programa" del que se predica la necesaria evaluación estratégica ambiental no se define en el Convenio de Aarhus, ni tampoco en la directiva europea, y acaso por ello haya podido recibir una interpretación un tanto reduccionista en su transposición ${ }^{95}$, a nuestros efectos ha de notarse que unos y otros se sitúan en principio en la cabecera de la correspondiente política pública y en una etapa temprana (de infraestructuras de transporte, agricultura o energía, por ejemplo $)^{96}$, a fin de que la evaluación ambiental que se haga en esa fase termine por condicionar, a modo de cascada, las normas vinculantes que en su momento hayan de dictarse, sean de naturaleza reglamentaria o legal ${ }^{97}$.

94 Por ejemplo, en el caso español, la Ley 21/2013, de 9 de diciembre, de evaluación ambiental, artículo 3 .

95 Así, el artículo 5.2 de la Ley española 21/2013, del 9 de diciembre, de evaluación ambiental que entiende por "Planes y programas" el conjunto de estrategias, directrices y propuestas destinadas a satisfacer necesidades sociales, no ejecutables directamente, sino a través de su desarrollo por medio de uno o varios proyectos. 
Basten los citados ejemplos para señalar que el derecho del medio ambiente apuesta por una participación dialogada y colaborativa entre la Administración y el resto de actores, públicos y privados, puesto que la decisión final habrá de fundarse en la información obrante una vez evaluada oportunamente ${ }^{98}$.

\subsection{EN PARTICULAR, LA ELABORACIÓN DE DISPOSICIONES GENERALES EN PROCEDIMIENTOS DE AMPLIA PARTICIPACIÓN}

A efectos explicativos, cabe recapitular cuanto ha quedado dicho en punto a los procedimientos administrativos de amplia participación, por referencia a la elaboración de normas infralegales y disposiciones generales ${ }^{99}$, y por comparación con los sistemas de elaboración más tradicionales.

Por justa convención, como se ha visto, puede distinguirse entre la elaboración a través de un modelo participativo de vía estrecha y menos formalizado (como el propio de la información pública al que antes se ha aludido) o de un segundo modelo, de amplia participación (como, por ejemplo, el vigente en el esquema norteamericano de la Administrative Procedure Act, de 1946, o en algunos procedimientos establecidos en el derecho de la Unión Europea, como en materia de medio ambiente) ${ }^{100}$.

En lo que ahora importa, las diferencias entre ambas modalidades se podrían sintetizar del modo siguiente:

- La participación en el primer modelo limita el número de participantes a los interesados en sentido estricto; se proyecta esencialmente sobre los derechos e intereses afectados por la disposición de carácter general ${ }_{i}$ no presupone la obligación de la Administración de entrar en diálogo (ponderación, motivación) con las alegaciones vertidas en el trámite de información pública ${ }_{i} y_{\text {, }}$

98 La participación aquí se corresponde en términos generales con las características propias de la que hemos venido en llamar tercera generación. Me remito a mi trabajo "Algunas respuestas del derecho administrativo contemporáneo ante las nuevas formas de regulación: fuentes, alianzas con el derecho privado, procedimientos de tercera generación", en Innovación y reforma en el derecho administrativo, 2.0, Sevilla: Global Law Press - Editorial Derecho Global, 2012; y "Towards a Third Generation of Administrative Procedures", en Susan-Rose Ackerman y Peter L. Lindseth (eds.), Comparative Administrative Law, Vermont: Edward Elgar Publishing, 2010. Véase también Susan-Rose Ackerman, Peter L. Lindseth y EMERSOn BlaKe, Three generations of Administrative Procedures in Comparative Administrative Law, 2. ${ }^{a}$ ed., UK, USA: Edward Elgar Publishing, 2017.

99 Lo que incluye no solo la elaboración de anteproyectos de ley o de programas y planes de políticas públicas, sino instrumentos de derecho blando, tales como recomendaciones o directrices.

100 Como ejemplo derivado del derecho de la Unión Europea puede citarse el procedimiento de evaluación estratégica ambiental. Sobre el modelo norteamericano, véase Peter Strauss "Los procedimientos de elaboración de reglamentos y de disposiciones administrativas en EE. Uu.", en La transformación del procedimiento administrativo, Sevilla: Global Law Press - Editorial Derecho Global, 2008, pp. 303 y ss. 
finalmente, se produce en un momento tardío, puntual y breve en los plazos ${ }^{101}$. En otras palabras, se trata de una participación limitada, que no conecta por las razones indicadas con el principio democrático, sino con el principio del Estado de derecho.

- La participación en el segundo modelo, al menos idealmente, se mueve en dirección contraria: primero, se extiende no solo a los interesados, sino también al público en general (o al público interesado en sentido amplio), con posible participación de los expertos y de otras Administraciones, eventualmente transfronterizas también, en función de la materia y del objeto ${ }^{102}$; segundo, en cuanto a su ámbito, es susceptible de alcanzar no solo a los derechos e intereses implicados, sino también a la formulación de la política de que se trate $y$, por tanto, a cuestiones de oportunidad y conveniencia, incorporando una dimensión positiva (o constructiva) ${ }_{i}$ tercero, se caracteriza por un diálogo real (ponderación, motivación, eventuales nuevas rondas participativas) i y, cuarto, no se produce en un momento tardío, puntual y con plazos fugaces, sino que acompaña a toda la vida del acto jurídico en cuestión (norma infralegal, plan, programa, evaluación, convenio, contrato, por ejemplo), esto es, a su preparación previa, a su elaboración y aprobación, y a su ejecución y revisión y reforma. Dicho de otro modo, se trata de una participación de vía ancha, en lo que hace a los participantes, al objeto, al diálogo "Administración-individuo", $\mathrm{y}$ a las fases temporales en que se sustancia.

\section{LA FINALIDAD A LA QUE RESPONDE LA PARTICIPACIÓN EN CADA CLASE DE PROCEDIMIENTO Y SU RELACIÓN CON EL PRINCIPIO DEMOCRÁTICO}

Como se desprende de los ejemplos extraídos, la mayor parte de las modalidades de participación en los procedimientos administrativos descritos no son expresión del principio democrático:

101 Por ejemplo, el artículo 26.6 de la Ley del Gobierno, citada en nota anterior, prescribía: "El plazo mínimo de esta audiencia e información públicas será de 15 días hábiles, y podrá ser reducido hasta un mínimo de siete días hábiles cuando razones debidamente motivadas así lo justifiquen, así como cuando se aplique la tramitación urgente de iniciativas normativas, tal y como se establece en el artículo 27.2. De ello deberá dejarse constancia en la Memoria del Análisis de Impacto Normativo".

102 Así, entre otros actos jurídicos a distintos niveles, se dispone en la Directiva 2001/42/CE del Parlamento Europeo y del Consejo del 27 de junio de 2001, relativa a la evaluación de los efectos de determinados planes y programas en el medio ambiente. 
8.1. LA PARTICIPACIÓN EN LOS PROCEDIMIENTOS TRADICIONALES QUE TIENEN POR OBJETO EL DICTADO DE ACTOS ADMINISTRATIVOS: DERECHOS DE DEFENSA

La participación en los procedimientos tradicionales -los que desembocan en actos administrativos que afectan a los derechos e intereses y pueden ser, al menos potencialmente, desfavorables o de gravamen- carece de toda dimensión democrática. La participación, en cualesquiera de sus formas -en el curso de la instrucción, mediante la audiencia del interesado, en primer lugar, pero también en la práctica de las pruebas, en las alegaciones vertidas ante la propuesta de resolución, por ejemplo- no tiene otro sentido que el de la defensa y promoción de los propios derechos e intereses, justamente de la posición jurídica del interesado. Es el principio del Estado de derecho el que en términos constitucionales ofrece fundamento a esta clase de participación.

\subsection{LA PARTICIPACIÓN EN LOS PROCEDIMIENTOS TRADICIONALES PARA LA ELABORACIÓN DE DISPOSICIONES GENERALES: DEFENSA Y PROMOCIÓN DE DERECHOS E INTERESES COLECTIVOS}

La participación en los procedimientos de elaboración de disposiciones generales al modo clásico - como el de vía estrecha- responde en última instancia a la idea de tutela y protección de los afectados, esto es, de la defensa, bien sea de intereses individuales, o bien y sobre todo de intereses colectivos, de derechos difusos, como ha quedado dicho. Se trata, según nos consta, de una participación que tiene lugar sustancialmente a través de trámites como el de la información pública.

En estos casos, tampoco puede decirse que la participación fortalezca la legitimidad democrática del acto jurídico final, sino que se funda en el principio del Estado de derecho.

\subsection{LOS PROCEDIMIENTOS DE AMPLIA PARTICIPACIÓN: UNA PLURALIDAD DE FINES}

El ejemplo de la legislación de medio ambiente de matriz europea pone de relieve que el objetivo inmediato de la participación reside en dar la oportunidad real de influenciar la decisión que finalmente se adopte. Entronca en ese sentido con el principio democrático, cuando concurren las condiciones antes señaladas.

Se trata, por otra parte, de influir, y no necesariamente de codecidir. Aun cuando participen múltiples actores y cada uno lo haga a título propio (interesados, público en general, expertos, Administraciones transfronterizas, por ejemplo), a la postre es la Administración competente en cada caso la que ha de resolver y tomar la decisión que corresponda. Esta podrá separarse del parecer expresado por una amplia mayoría de participantes, si tiene buenas razones para ello y así lo pondera, argumenta, justifica y motiva suficientemente. La 
participación ciudadana en estos procedimientos no consiste en un referendo; no representa una vía de participación democrática directa.

Con todo, estos procedimientos administrativos tienden claros lazos con el principio democrático o, dicho más en concreto, pueden resultar expresivos de la "legitimación mediante el procedimiento" cuando se da entrada a una abierta y extensa participación para, entre todos, colaborar en el hallazgo de la solución no prevista en la ley, y establecer nuevas normas o reglas de modo deliberativo o discursivo. Como se ha visto, en los procedimientos creativos o innnvadores cuyo objeto sea un acto jurídico de alcance general, y no un acto meramente aplicativo, la participación adquiere un peso y relieve específicos, si realmente se erige en el eje del procedimiento por su función de complemento y concreción de la ley. Es, según sabemos, una participación extensa; abierta, comprensiva de una multiplicidad de intereses públicos, privados y mixtos; y, además, discursiva o deliberativa, en la medida en que el procedimiento da curso a una suerte de diálogo. Esas condiciones permitirían hablar de una conexión entre esta clase de procedimiento administrativo y la legitimidad democrática, esto es, una participación que es susceptible de transmitir una legitimidad democrática adicional a la que ofrece la ley parlamentaria respecto de la acción administrativa.

Por otra parte, aun en el caso del medio ambiente, marcado como se ha dicho por esa clase de participación, podemos identificar otras finalidades que no guardan necesariamente una relación tan directa con el principio democrático.

Así, y a título de ejemplo, la Declaración de Río de Janeiro parece basar la participación asimismo en razones de eficacia (los problemas medioambientales se enfrentan mejor cuando participan todos los afectados, dice el principio 10) ${ }^{103}$; o en la inclusividad y la no discriminación (principio $20^{[104]}$ y principio 22$)^{105}$.

También el Convenio de Aarhus afirma que, en la esfera del medio ambiente, un mejor acceso a la información y una mayor participación del público en el proceso decisorio permiten adoptar mejores resoluciones y aplicarlas más eficazmente; contribuyen a sensibilizar al público respecto de los problemas ambientales; le dan la posibilidad de expresar sus preocupaciones; y ayudan a

103 Río de Janeiro, principio 10: "Environmental issues are best bandled with participation of all concerned citizens, at the relevant level. At the national level, each individual shall bave appropriate access to information concerning the environment that is beld by public autborities, including information on bazardous materials and activities in their communities, and the opportunity to participate in decision-making processes. States shall facilitate and encourage public awareness and participation by making information widely available. Effective access to judicial and administrative proceedings, including redress and remedy, shall be provided" (Disponible en línea http://www.un-documents.net/rio-dec.htm).

104 "Women bave a vital role in environmental management and development. Their full participation is therefore essential to achieve sustainable development."

105 "States should recognize and duly support their identity, culture and interests and enable their effective participation in the acbievement of sustainable development". Principios estos, a la postre, emparentados con el principio democrático. 
las autoridades públicas a tenerlas debidamente en cuenta ${ }^{106}$. La toma de decisiones basadas en la mejor información disponible, la generación de consenso, la corresponsabilidad e implicación ciudadana son algunas de esas finalidades, conectadas de alguna forma con valores, principios y derechos fundamenta$\operatorname{les}^{107}$. Se persigue a la postre una mayor eficacia, un mejor resultado ${ }^{108}$.

Otros Convenios patrocinados por la UNCE, como el Convenio sobre la evaluación estratégica ambiental, adoptado el 21 de mayo de $2003^{[109]}$, siguen la misma línea del Convenio de Aarhus, con un marcado propósito inclusivo de los afectados por los efectos transfronterizos de los planes y programas. Por lo demás, la Unión Europea se inscribe en la misma estela ${ }^{110}$.

Sea como fuere, y con independencia de la relación que guarden esos criterios con el principio democrático, lo cierto es que no se contradicen con este, sino que se suman. Importa, eso sí, que el diseño legal del procedimiento -y su práctica real- dé respuestas adecuadas a la necesidad de una participación real y efectiva.

\subsection{El CASO DE LA AUtonomía LOCAL}

Además de los supuestos que acaban de exponerse en relación con el ámbito del medio ambiente, podría traerse ahora el ejemplo de la Carta Europea de Autonomía Local"111, de acuerdo con la cual "el derecho de los ciudadanos a

106 Cfr. Preámbulo.

107 Entre los derechos, cabría citar el derecho a la vida, a la integridad física, al medio ambiente, a la información o a la igualdad, fundados en última instancia a su vez en la dignidad humana (véase, por ejemplo, el artículo 10.2 C.E.).

108 A ello responden la adopción de medidas basadas en la mejor información disponible -lo que incluye el parecer del público y no solo el conocimiento experto-; y una mayor efectividad de las medidas, es decir, que estas alcancen los objetivos pretendidos, y ello tanto por su más fácil aceptación por los afectados fruto de la deliberación, como por el efecto positivo que genera la transparencia y el control (en primer término, de la Administración responsable).

109 Véase Protocol on strategic environmental assessment to the convention on environmental impact assessment in a transboundary context.

110 Transposición del Convenio Aarhus mediante la Directive 2003/4/EC of the European Parliament and of the Council of 28 January 2003 on public access to environmental information and repealing Council Directive 90/313/EEC, y el Reglamento (CE) núm. 1367/2006 del Parlamento Europeo y del Consejo, de 6 de septiembre de 2006, relativo a la aplicación, a las instituciones y a los organismos comunitarios, de las disposiciones del Convenio de Aarhus sobre el acceso a la información, la participación del público en la toma de decisiones y el acceso a la justicia en materia de medio ambiente. Junto a una finalidad directamente vinculada a la idea de influenciar decisivamente la decisión final mediante una amplia y efectiva participación, emergen, en efecto, otros objetivos, tales como la aceptación y generación de consenso entre los destinatarios, la lucha contra la discriminación, o la mayor eficacia e implicación de todos en relevantes políticas públicas, entre otros.

111 Hecha en Estrasburgo el 15 de octubre de 1985. 
participar en la gestión de los asuntos públicos forma parte de los principios democráticos comunes a todos los Estados miembros del Consejo de Europa"112, y que, como concreta su Protocolo Adicional ${ }^{113}$, el derecho a participar en los asuntos de interés local aspira a determinar o influir el ejercicio de las potestades y competencias del ente local ${ }^{114}$

Por su parte, el reconocimiento del derecho individual a participar en el ámbito local, afirma el Informe que acompaña al citado Protocolo ${ }^{115}$, responde a tres razones fundamentales: la participación contribuye a fortalecer la legitimidad de las decisiones y a promover la rendición de cuentas; la participación permite que las autoridades públicas obtengan una mejor información para diseñar mejores políticas y servicios ${ }^{116} ;$ y la participación posee un valor intrínseco por cuanto proporciona un sentido de pertenencia a la comunidad local ${ }^{117}$. Responde, pues, a una pluralidad de fines.

En esta sede, conviene hacer tres precisiones:

- Primera, el ente local está dotado de una legitimidad democrática directa, cualitativamente distinta y superior por cierto a la de cualquier otra Administración dotada de legitimidad funcional (como, por ejemplo, la universidad). La gestión de los asuntos locales, y esto es lo que quiere ahora subrayarse, se sitúa entre dos coordenadas constitucionales, en una suerte de doble legitimación democrática, característica de los entes locales, a saber: de un lado, la legitimidad democrática que les es propia y que procede de la directa elección de sus

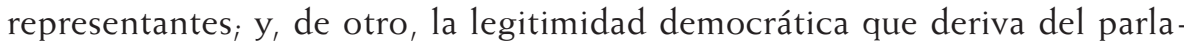
mento -legítimo representante del pueblo en su conjunto- y que se obtiene mediante la observancia de las leyes ${ }^{118}$. A la luz de esta premisa, podría sugerirse, la Administración local estaría menos urgida a una "legitimación mediante el procedimiento", esto es, a una participación amplia que permita rellenar el contenido material de la ley, desde el momento en que sus representantes gozan de una mayor legitimidad, que la de una Administración ministerial. No es esta, sin embargo, una conclusión que quepa suscribir sin más, puesto que el legislador parlamentario es libre de establecer o arbitrar procedimientos administrativos dotados de las características antes reseñadas para otorgar un

112 Cfr. tercer considerando.

113 Utrecht, 16 de noviembre de 2009.

114 Artículo 1

115 Ibíd.

116 La participación en los escenarios marcados por el riesgo y la incertidumbre, la generación de conocimiento (proveniente del público en general, de los expertos y técnicos, de otras Administraciones) adquiere una importancia capital. Esta relevante circunstancia dota a la participación, en contraste con una consulta o referendo local, de un contenido menos político, más complejo o menos libre en ocasiones, en cuanto a las opciones.

117 Ibíd., B. General Remarks.

118 Sobre el tema, puede verse EBERHARD SCHMidT-AsSMANn, La teoría general del derecho administrativo como sistema, óp. cit., capítulo segundo, núm. marg. 89. 
plus de legitimidad democrática a lo resuelto en el procedimiento. Pertenecen desde luego a la libre esfera del legislador de la autonomía local dos cosas: una, configurarla de modo que su ejercicio haya de complementarse con carácter general mediante la participación de los vecinos en cualesquiera de sus modalidades, y otra, establecer por sectores (urbanismo, u organización de los servicios públicos locales, por ejemplo) amplios mecanismos participativos.

- Segunda, la mayor cercanía y proximidad de la Administración local a los individuos, así como las tareas y competencias que esta tiene encomendadas, permiten fórmulas más flexibles de participación, tanto en lo que hace a fenómenos de democracia participativa (una consulta o encuesta, por ejemplo), como a los casos de procedimientos administrativos de amplia participación (para aprobar un instrumento de planeamiento urbanístico general, por ejemplo).

- Tercera, esa doble perspectiva obliga a nivel local a extremar la distinción conceptual entre ambos planos: la democracia participativa y la democracia directa, de un lado, y la legitimación a través del procedimiento, de otro. Así, guardan relación con la primera aquellas formas de democracia participativa que el propio Protocolo Adicional contempla sin carácter exhaustivo: consultas, referendos locales, peticiones, comunicación a través de sugerencias y reclamaciones, o el acceso a la información administrativa ${ }^{119}$. A través de ellas se refleja sin duda la riqueza y diversidad de las técnicas participativas y de los procedimientos establecidos a todos los niveles, y cuyo objeto en última instancia se localiza en el derecho a participar en la vida pública en la esfera local, y el derecho a obtener información de las entidades locales ${ }^{120}$. Esas u otras expresiones de democracia participativa resultan tanto más asequibles cuanto menor complejidad técnica o científica presenten los asuntos. Debatir públicamente sobre la ubicación de una infraestructura o de las zonas verdes, por ejemplo, a nivel local puede resultar más factible que deliberar sobre la peligrosidad de las sustancias químicas, cuya competencia por lo demás está atribuida a las plantas superiores de gobierno. En cambio, la toma de posición respecto de grandes opciones políticas es susceptible de canalizarse con naturalidad a través de esos instrumentos de democracia participativa, más profusos por otra parte a nivel local.

Aquí nos ocupamos, sin embargo, de los segundos, esto es, de los procedimientos administrativos que, también a nivel local, tienen por objeto rellenar el contenido material de la ley (legitimación a través del procedimiento) y cuya razón de ser no estriba en pulsar sin más la opinión de los vecinos sobre un aspecto puntual o esporádico, sino en involucrarlos activamente en determinadas políticas públicas, en establecer una suerte de "diálogo" o "conversación"

119 Artículo 2.2.ii.

120 Cfr. Council of Europe Treaty Series - n. ${ }^{\circ} 207$ to the Additional Protocol to the European Charter of Local Self-Government, Explanatory Report on the right to participate in the affairs of a local authority, Utrecht, 16.XI.2009, A. 
para la gestión ordinaria de una determinada política pública, como pudieran ser el urbanismo o el medio ambiente local.

El procedimiento que sirve de vehículo de la democracia participativa a nivel local -una consulta, por ejemplo- resulta de ordinario más sencillo de articular que el procedimiento en que se ventila el ejercicio de políticas públicas de singular trascendencia -y de nuevo el caso del urbanismo resulta apropiado-, puesto que no es lo mismo canalizar una consulta, que un diálogo continuado en el tiempo, en el ciclo temporal completo de una política pública. El legislador ha de establecer las reglas adecuadas para cada clase de participación. Uno y otro fenómeno (democracia participativa y legitimación a través del procedimiento), tal como implícitamente han quedado caracterizados en las páginas precedentes, no son intercambiables y responden a finalidades inmediatas distintas, aun cuando en última instancia sean reconducibles a un tronco común.

\section{UN EJEMPLO DE AUTONOMÍA FUNCIONAL DE LA ADMINISTRACIÓN. EL CASO DE LA PARTICIPACIÓN EN LOS ÓRGANOS COLEGIADOS DE LAS UNIVERSIDADES PÚBLICAS}

A efectos de deslinde conceptual, una mención especial merece, en este sencillo ejercicio de delimitación entre democracia y participación en los procedimientos administrativos, la participación en los órganos de las universidades públicas dotadas de autonomía en versión española ${ }^{121}$.

\subsection{LA DIFERENCIA ENTRE LEGITIMIDAD DEMOCRÁTICA DE LA AUTONOMÍA LOCAL Y LA AUTONOMÍA FUNCIONAL DE CIERTAS ADMINISTRACIONES (EL CASO DE LA UNIVERSIDAD PÚBLICA)}

Para entender el fundamento y los límites de la autonomía funcional, resulta ilustrativo comparar la autonomía universitaria, de un lado, con la autonomía local, de otro ${ }^{122}$. Por apuntar lo más obvio: a diferencia de los responsables municipales salidos de unas elecciones locales, los profesores no son representantes del pueblo, elegidos democráticamente, como tampoco lo son los estudiantes o el personal de administración y servicios. Las personas que ejercen el autogobierno de la universidad carecen de legitimidad democrática personal.

Tampoco las "competencias" de la universidad presentan un carácter "universal", ni estas disfrutan de una cláusula general que cubra la posible gestión de todos sus eventuales intereses como sucede con los entes locales. Las 
competencias y potestades se hallan estrictamente "funcionalizadas" al servicio de unos específicos fines (docentes e investigadores, en esencia).

Por lo demás, una universidad, como Administración funcional, ejerce sus potestades en régimen de autorregulación; su objeto inmediato o propio no consiste en regular hacia fuera, en establecer normas o disciplinar intereses extra muros de la Administración universitaria para el conjunto de la comunidad. La autonomía universitaria, y valga la simplificación, se establece en garantía de las libertades educativas, de la libertad científica y artística. No cabe confundir, en suma, la legitimidad democrática de los municipios, con la legitimidad funcional de las llamadas Administraciones funcionales ${ }^{123}$.

\subsection{LA PARTICIPACIÓN EN LA GESTIÓN ORDINARIA DE LA UNIVERSIDAD}

A nuestro propósito, cabría distinguir a grandes trazos dos supuestos básicos de participación en los órganos universitarios en función de las materias y

123 La participación ciudadana o la participación de los miembros de una corporación, por ejemplo, no atribuye, ni genera, legitimidad democrática. La doctrina y la jurisprudencia constitucional alemanas han abundado en esta diferenciación. La voluntad popular circunscrita territorialmente al municipio podría ser concebida como "pueblo" a los efectos de entenderse como "sujeto legitimador" en términos democráticos, naturalmente en el marco de las leyes (puede verse Hans Heinrich TruTe, óp. cit., p. 346). Ahora bien, con carácter general, sin embargo, la jurisprudencia constitucional advierte que la voluntad popular se corresponde con el pueblo, entendido como generalidad o colectivo de ciudadanos de modo indiferenciado. Cuando a una Administración el legislador le atribuye una función y le dota de cierta autonomía funcional (un hospital, la radio y televisión pública, una universidad, un colectivo profesional), está haciendo una diferenciación, un acotamiento del "pueblo", puesto que no todos forman parte de esa Administración. En esos casos, es evidente que sus miembros no son el "pueblo" a efectos del principio democrático. La participación selectiva de un grupo de personas, esto es, los miembros de esa Administración a través de la cual se gestionan unos concretos intereses, no equivalen al "pueblo" y, por tanto, esa participación no es susceptible de transmitir legitimidad democrática alguna. La doctrina mayoritaria alemana entiende por Administraciones funcionales aquellas unidades administrativas dotadas de autonomía para el cumplimiento de funciones específicas, es decir, no universales (valgan los ejemplos del párrafo anterior), que no se definen primariamente en razón del territorio, como ocurre con la autonomía local. La pertenencia a esas Administraciones puede presentar un carácter homogéneo (una profesión) o heterogéneo (una universidad: profesores, estudiantes, personal de administración). Sus miembros no son elegidos por el pueblo, no ostentan representación alguna. Todos sus integrantes participan en la gestión de los intereses que les son propios. La determinación de las competencias, de las funciones, de la organización y de los procedimientos de cada Administración funcional compete al legislador. Y es esta una tarea fundamental. En su configuración, el legislador ha de fijar con claridad las competencias y las funciones que haya de atribuirse a cada órgano de esas Administraciones, de modo que su ejercicio pueda ser supervisado por una autoridad legitimada democráticamente. Es obvio, por lo demás, que el legislador no podría atribuirle a una Administración funcional competencias que excedan del círculo de intereses afectados (sobre este último extremo, véase DiRK EHLERS, HANS-Uwe ERICHSEN y MARTin BurGi, Allgemeines Verwaltungsrecht, 15. ${ }^{a}$ ed., Berlin: De Gruyter, 2015, p. 244). 
su conexión con los bienes, valores y derechos que subyacen a la autonomía universitaria. De un lado, la participación en los órganos colegiados cuando resuelven cuestiones ajenas al núcleo duro de la autonomía universitaria -esto es, cuando sus decisiones no entroncan con, ni son emanación de, los fines a los que esta constitucionalmente sirve-, como puede ser la decisión relativa a la organización de un curso y su horario, o la concerniente a la distribución de un presupuesto entre departamentos, o la atinente a la participación en comisiones para la selección del personal docente a contratar, por ejemplo. Y, de otro, la participación en los órganos colegiados cuando, por el contrario, se ocupan, en los términos legalmente establecidos, de temas que guardan una directa relación con ese núcleo duro o son, por mejor decir, materias propias de la autonomía universitaria, como pudiera ser el desarrollo de un plan de estudios.

En el primer caso, esa participación da cauce simple y llanamente a la autogestión, como ya notábamos. Si a los profesores corresponde resolver esas materias es a consecuencia de una decisión del legislador y no constituye una emanación obligada o necesaria de la autonomía universitaria en términos constitucionales. Esa participación, pues, no expresa principio democrático alguno, aun cuando el principio del voto mayoritario o del voto ponderado presida la toma de esa clase de decisiones. La universidad no es "más democrática" por autogestionarse. Estamos ante un supuesto de mera autorregulación en su grado más primario o elemental. Pocas reservas, por otra parte, se le pueden objetar al legislador, si decide diferir estos asuntos a la propia organización a la que dota de autonomía funcional.

\subsection{LA PARTICIPACIÓN EN LOS ASUNTOS RELACIONADOS \\ CON LAS LIBERTADES EDUCATIVAS Y LA PROTECCIÓN INSTITUCIONAL QUE BRINDA LA AUTONOMÍA UNIVERSITARIA}

En el segundo -es decir, ante asuntos derivables de, o conectados directamente con, la autonomía universitaria- esa autorregulación presenta una dimensión jurídica distinta y más relevante.

Sin embargo, tampoco en este caso la decisión que tome la universidad conecta con el principio democrático por el mero hecho de que se trate de una decisión participada y consensuada entre los profesores de esa universidad. La legitimidad democrática le viene, por el contrario, de la propia ley parlamentaria, no de la participación, y, más específicamente, del cumplimiento de los fines que esta establece y por los que se justifica la autonomía misma. En definitiva, si un plan de estudios responde a las exigencias dimanantes de la ciencia y del arte en cada momento, con exclusión de cualquier otra consideración, podrá decirse que la participación conecta con el principio democrático, por hallarse dentro del perímetro de cobertura que la ley ofrece.

La autonomía reconocida para la elaboración o desarrollo de un plan de estudios no lo es para que los participantes decidan lo que tengan por 
conveniente o mejor se avenga a sus intereses profesionales o de los de grupo, escuela o estamento, sino para que hagan realidad y concreten los fines que la ley ha marcado para la realización de un plan de estudios (al servicio de la ciencia y de la profesión) ${ }^{124}$. En tal sentido, los planes de estudio solo serán válidos y, además, legítimos en términos democráticos, si responden a esos fines $^{125}$. Unos planes de estudio que obedecieran a las necesidades del empleo del profesorado traicionarían la finalidad perseguida por la ley, por lo que no solo incurrirían en desviación de poder, sino que carecerían de la legitimidad democrática necesaria ${ }^{126}$. En suma, no serían conformes a derecho, ni, por tanto, democráticos.

\subsection{LA CADENA DE LEGITIMACIÓN DEMOCRÁTICA Y LA LEGITIMACIÓN}

\section{A TRAVÉS DEL PROCEDIMIENTO}

Mientras la Administración de carácter ministerial se legitima, en su caso, mediante la teoría de la cadena de legitimación (aquí, podríamos renovar la metáfora con el ejemplo de la fibra óptica o del ADSL), la actuación de los órganos

124 Así, por ejemplo, en el caso español, la Ley Orgánica de Universidades, 6/2001, del 21 de diciembre, dispone en su artículo 1.2 lo siguiente:

"Son funciones de la universidad al servicio de la sociedad:

a) La creación, desarrollo, transmisión y crítica de la ciencia, de la técnica y de la cultura.

b) La preparación para el ejercicio de actividades profesionales que exijan la aplicación de conocimientos y métodos científicos y para la creación artística.

c) La difusión, la valorización y la transferencia del conocimiento al servicio de la cultura, de la calidad de la vida, y del desarrollo económico.

d) La difusión del conocimiento y la cultura a través de la extensión universitaria y la formación a lo largo de toda la vida."

125 En ocasiones, como la experiencia pos-1968 ha puesto de manifiesto, la participación ha llevado en la práctica a la persecución de intereses menores, sin relación e incluso en contradicción con la libertad y el desarrollo de la ciencia. Cfr. Eduardo García de EnTerría,

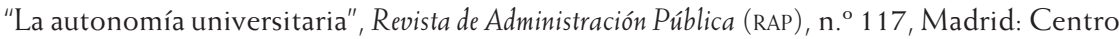
de Estudios Políticos y Constitucionales, 1988, p. 17.

126 Los riesgos de confiar a un colectivo o estamento interesado (el profesorado) la confección de planes de estudio son evidentes, puesto que ello exige de entrada evaluar cuestiones que exceden en mucho de su visión y conocimiento experto (las necesidades laborales del mercado, la evolución de la población, los valores que han de preservarse en los diferentes ejercicios profesionales que derivan de cada titulación, etc.). A lo que se suma la fácil tentación de diseñar un plan en función de su tradicional punto de vista y, lo que es más grave, de sus intereses de promoción profesional. Para conjurar esos riesgos, de un lado, y fortalecer la legitimidad democrática de algo tan determinante y decisivo para la entera sociedad como son los planes de estudio que habilitan para el ejercicio de múltiples profesiones, de otro, parece obligado confiar al legislador el establecimiento de las bases del sistema. La atribución de un poder tan formidable, como es la aprobación de los planes de estudio (aunque fueren luego formalmente aprobados por la Administración territorial competente) son evidentes y harían sonreír por su ingenuidad a los cultivadores de la public choice theory. 
universitarios se legitima -como sucede con los organismos reguladoresmediante la "teoría del WiFi": mientras esa acción no se salga de la cobertura que la ley otorga, esto es, en tanto no se sustraiga del perímetro de los fines legalmente establecidos, tal acción estará legitimada ${ }^{127}$. La misma autonomía universitaria, nótese bien, se garantiza en el bien entendido de que, lejos de asimilarse a la autonomía local -dotada de una representatividad directa-, se ejerce al exclusivo servicio de los fines que la Constitución -defensa institucional frente a la injerencia política sobre los contenidos de la ciencia- y la ley marcan.

Esa legitimidad democrática, conviene insistir, deriva tan solo del cumplimiento de los fines constitucional y legalmente establecidos para el ejercicio de sus potestades. No proviene, en cambio, de la legitimidad personal de sus miembros, ya que no han sido elegidos por el pueblo.

Finalmente, tampoco cabe hablar de una legitimación material con apoyo en el procedimiento participativo, puesto que la participación no es susceptible de satisfacer las condiciones a las que antes se ha aludido, señaladamente porque se halla limitada a sus miembros, a la satisfacción de unas finalidades específicas, en modo alguno conectable con la generalidad, sin que tenga en consecuencia cabida la participación de otros colectivos.

La universidad, pues, disfruta, aun en lo que hace al núcleo duro de la autonomía, de una legitimidad autónoma amparada en la ley, derivada de la satisfacción de los fines que la ley establece, pero no de una legitimidad democrática que resulte de la participación de sus miembros ${ }^{128}$.

\subsection{Cuando el ejercicio de la autonomía funcional excede DEL CÍRCULO DE INTERESES DE SUS MIEMBROS}

La universidad presenta algunas singularidades respecto de otras Administraciones dotadas de autonomía funcional. Y es que sus decisiones exceden en cierto modo del perímetro de intereses de sus miembros (no es, por ejemplo, una corporación profesional, como un colegio de abogados), puesto que ante todo se trata de un servicio público, entendido este en sentido amplio, con una intensa proyección exterior o hacia fuera de la propia universidad. Baste pensar que el ejercicio de tantas profesiones se ve condicionado de modo directo por los planes de estudio y por las prestaciones que la misma universidad ofrezca (calidad de la docencia e investigación).

En otras palabras, la participación en el ámbito de la universidad -y de los múltiples procedimientos en que se canaliza- no se reconoce para que esta

127 O, si se prefiere otra imagen, se satisface el principio democrático siempre que se sintonice la radio, sin interferencias, esto es, con los fines atribuidos.

128 Eberhard Schmidt-Assmann, La teoría general del derecho administrativo como sistema, óp. cit., capítulo segundo, núm. marg. 81 . 
se sirva a sí misma, defienda sus propios intereses, sino a terceros (usuarios del servicio) y atienda los fines que la trascienden (investigación, docencia).

En ese contexto, y desde la perspectiva del principio democrático, ha de reconocerse la fragilidad que presenta un sistema de transmisión de legitimidad democrática basado exclusivamente en la teoría del Wifi-esto es, en el cumplimiento de unos objetivos-, y donde ninguno de los miembros, ni de sus órganos de gobierno, ha sido elegido por el pueblo (falta de legitimidad personal), siendo así que la participación no está abierta al exterior, a la generalidad, y, por tanto, no cabe hablar tampoco de una legitimidad material complementaria. Todo se fía, en última instancia, a que esos fines se observen en las actividades de cada universidad, en el seno de cada procedimiento. Las garantías jurídicas para que una Administración dotada de autonomía funcional como la universidad no pierda la cobertura legal y no se extralimite de los fines institucionales a los que propende o responde (la libertad científica) son de una enorme debilidad, por decir lo menos.

La situación se complica cuando, como en el caso español, la autonomía universitaria que el legislador ordinario ha querido atribuir a la Administración desborda lo que resulta constitucionalmente exigible ${ }^{129}$. Piénsese, de nuevo, en la elaboración de los planes de estudio. De un lado, como se ha apuntado, una participación mal entendida -como mera expresión de la democracia y, por tanto, "libre" en sus opciones, sin vinculación estricta a la finalidad para la que se otorga la potestad misma- podría derivar en decisiones, acaso consensuadas por sus partícipes, pero desviadas del fin-como sucedería en el caso de un plan de estudios entendido como "plan de empleo" del profesorado ya establecido-. De otro, mediante el plan de estudios se afectan no solo cuestiones que pertenecen a la universidad, sino a otros bienes, valores y derechos para los que no se halla habilitada.

Por lo que a este último extremo concierne, el legislador no puede olvidar que una cosa es la ciencia y otra la profesión, y que mientras la ciencia es libre

129 Esta afirmación requiere una mayor fundamentación que en esta sede no cabe ofrecer habida cuenta del carácter colateral del ejemplo y de la afirmación. Pero baste, para comprobarlo, la lectura del artículo 2 de la Ley 6/2001 citada, y de otros preceptos de la misma (como los artículos 62 y ss. sobre la atribución a las universidades de la organización de la segunda fase de la selección del profesorado -el concurso-), a la luz, claro está, de la jurisprudencia constitucional y de la doctrina comparada. No cabe aquí más que recordar la doctrina sentada por la primera Sentencia de Tribunal Constitucional español que se ocupó con mayor detalle de la materia: el fundamento y justificación de la autonomía universitaria que el artículo 27.10 C.E. reconoce está en el respeto a la libertad académica, es decir, a la libertad de enseñanza, estudio e investigación. La protección de estas libertades frente a injerencias externas constituye la razón de ser de la autonomía universitaria, la cual requiere, cualquiera que sea el modelo organizativo que se adopte, que la libertad de ciencia sea garantizada tanto en su vertiente individual cuanto en la colectiva de la institución, entendida esta como la correspondiente a cada universidad en particular y no al conjunto de las mismas, según resulta del tenor literal del artículo 27.10. 
y a la universidad corresponde cultivarla sin injerencia política, el ejercicio de la profesión derivable de cada ciencia, por el contrario, afecta a la sociedad en su conjunto, a los consumidores y usuarios, a la defensa de la competencia o a la empleabilidad del titulado, a los derechos de los ciudadanos, por citar tan solo alguno de los bienes y valores en juego. Cuando una autonomía universitaria concebida tan expansivamente se extiende por esos campos, para los que carece de pericia, competencia técnica, perspectiva y, desde luego, de legitimidad democrática, el resultado es deficitario por más de un concepto. Se entiende que en otros ordenamientos jurídicos, en donde por cierto la autonomía universitaria al modo contemporáneo ha sido incubada, como en Alemania, los planes de estudio sean establecidos por el propio legislador (representante del pueblo), y no por la universidad (a la universidad le resta un desarrollo menor de lo dispuesto en la ley). Es el legislador el que ha de decidir qué formación debe de recibir quien desee ejercer la profesión de médico, abogado, ingeniero o profesor. Otra cosa será el contenido de esas materias, que solo a la ciencia -que no se determina a base de votos-incumbe, a través de la universidad, establecer. Con mayor razón, y por citar otro ejemplo, es al legislador al que compete fijar el sistema de selección del profesorado, sin diferirlo a lo que cada universidad pueda disponer, para garantizar una distancia democrática y que el regulado no capture al regulador, a fin de evitar que la autonomía universitaria se convierta en una suerte de "sindicato" o peor aún "agencia de colocación" de sus propios miembros. El erróneo entendimiento de la participación de sus miembros en la autogestión y autonomía, de sus límites y de su sentido o finalidad, no es ajeno a tales desviaciones.

\section{LA PARTICIPACIÓN NO ES EXPRESIÓN NECESARIA DE LA DEMOCRACIA, NI EQUIVALE SIN MÁS A "DEMOCRACIA PARTICIPATIVA" O A "DEMOCRACIA DIRECTA"}

A resultas de cuanto antecede, cabe concluir que no toda participación adquiere trascendencia o relevancia democrática. Más participación no se resuelve siempre y en todo caso en más democracia. No son términos sinónimos, ni magnitudes equivalentes. Participación (en el procedimiento administrativo) y democracia no son realidades coextensas, ni intercambiables. De entrada, resulta obligado diferenciar de qué "participación" y de qué "democracia" se habla en cada caso. Solo si se cumplen unas estrictas y elementales condiciones cabe hablar de un plus de "legitimación (democrática) de la Administración a través del procedimiento". 


\section{BIBLIOGRAFÍA}

Ackerman, Susan-Rose, Peter L. Lindseth and Emerson Blake. Three generations of Administrative Procedures in Comparative Administrative Law, 2. ${ }^{\text {a }}$ ed., UK - USA: Edward Elgar Publishing, 2017.

BARnes, JaVier. "El procedimiento administrativo en el tiempo y en el espacio: una perspectiva histórica y comparada", Procedimiento administrativo. Aspectos generales del procedimiento administrativo, t. I, Buenos Aires: La Ley, 2012.

BARNES, JAVIER. "Algunas respuestas del derecho administrativo contemporáneo ante las nuevas formas de regulación: fuentes, alianzas con el derecho privado, procedimientos de tercera generación", en Innovación y reforma en el derecho administrativo, 2.0, Sevilla: Global Law Press - Editorial Derecho Global, 2012.

BARNES, JAVIER. "Introducción. Reforma e innovación del procedimiento administrativo", en La transformación del procedimiento administrativo, Sevilla: Global Law Press -Editorial Derecho Global, 2008.

BARNES, JAVIER. "Towards a third generation of administrative procedures", en S. RoseAckerman y P. Lindseth, (eds.), Comparative Administrative Law, Vermont: Edward Elgar Publishing, 2010.

Cohen-Eliya, Moshe y Iddo Porat. Proportionality and Constitutional Culture, Cambridge: Cambridge University Press, 2013.

De Bellis, Maurizia. "Procedural rule-making of European Supervisory Agencies (ESA). An effective tool for legitimacy?", TARN Working Paper Series, n. 12, Maastricht: Universidad de Maastricht, 2017.

Ehlers, Dirk, Hans-Uwe Erichsen y Martin Burgi. Allgemeines Verwaltungsrecht, 15. ed., Berlin: De Gruyter, 2015.

Frankfurter, Felix. "The Final Report of the Attorney General's Committee on Administrative Procedure: Foreword", Columbia Law Review, n. ${ }^{\circ} 41$, New York: Columbia University, 1941,

García de Enterría, Eduardo. "La autonomía universitaria", Revista de Administración Pública (RAP), n. ${ }^{\circ}$ 117, Madrid: Centro de Estudios Políticos y Constitucionales, 1988.

Gurlit, ElKe. "Der Eigenwert des Verfahrens im Verwaltungsrecht", Veröffentlichungen der Vereinigung der Deutschen Staatsrecbtslebrer, n. ${ }^{\circ}$ 70, Berlin: De Gruyter, 2011.

Mashaw, Jerry L., "Reasoned Administration: The European Union, the United States, and the Project of Democratic Governance", Faculty Scholarship Series, n. ${ }^{\circ} 1179$, New Haven: Yale University, 2007. 
Rossen-Stadtfeld, Helge. "Beteiligung, Partizipation und Offentlichkeit", en Grundlagen des Verwaltungsrechts, II, 2. ed., München: Beck, 2012.

SCHMIDT-ASSMANn, EBERHARD. La teoría general del derecho administrativo como sistema, Madrid: Marcial Pons - INAP, 2003.

SCHMidT-Assmann, Eberhard. "Der Verfahrensgedanke in der Dogmatik des öffentliches Rechts", en Verfabren als staats- und verwaltungsrechtliche Kategorie, Heidelberg: R. v. Decker \& C. F. Müller, 1984.

SCHMidt-Assmann, Eberhard. "Verwaltungslegitimation als Rechtsbegriff", Archiv des öffentlichen Rechts, n. ${ }^{\circ}$ 116, Heidelberg: Mohr Siebeck, 1991.

Schmidt-Assmann, Eberhard, y Wolfang Hoffman-Riem. §10, "Eigenständigkeit der Verwaltung", en Grundlagen des Verwaltungsrechts, t. II, 2. ${ }^{\text {a }}$ ed., München: Beck 2012.

Strauss, Peter. "Los procedimientos de elaboración de reglamentos y de disposiciones administrativas en EE. UU.", en La transformación del procedimiento administrativo, Sevilla: Global Law Press - Editorial Derecho Global, 2008.

Trute, Hans Heinrich. "Die demokratische Legitimation der Verwaltung", en Grundlagen des Verwaltungsrechts, vol. I, 2. ${ }^{a}$ ed., München: Beck, 2012.

TuCKer, Paul. Unelected Power: The Quest for Legitimacy in Central Banking and the Regulatory State, Nueva Jersey: Princeton University Press, 2018. 